\title{
Polymeric Hopkinson Bar-Confinement Chamber Apparatus to Evaluate Fluid Cavitation
}

\author{
M.C. Bustamante ${ }^{1} \cdot$ D. Singh $^{1} \cdot$ D.S. Cronin ${ }^{1}$
}

Received: 18 March 2017 / Accepted: 25 July 2017 / Published online: 17 August 2017

(C) The Author(s) 2017. This article is an open access publication

\begin{abstract}
Mild traumatic brain injury associated with blast exposure is an important issue, and cavitation of the cerebrospinal fluid (CSF) has been suggested as a potential injury mechanism; however, physical measurements are required to evaluate cavitation thresholds. Modifications to a Split Hopkinson Pressure Bar (SHPB) apparatus were investigated with the aim to generate localized fluid cavitation and measure the cavitation threshold of fluids. The proposed design incorporated a novel closed cavitation chamber to generate localized cavitation resulting from a reflected compression pulse, which was generated by a spherical steel striker and Polymethyl methacrylate (PMMA) incident bar. A numerical model of the incident bar was developed and validated with 24 independent tests (cross-correlation: 0.970-0.997), and this was extended to a numerical model of the apparatus including the chamber, validated with 27 independent tests (cross-correlation: 0.921 ) to predict the tensile fluid pressure in the chamber. Tests on distilled water were performed with comparable numerical results for the chamber strain $\left(\mathrm{R}^{2}: 0.875\right)$ and chamber end-wall velocity $\left(\mathrm{R}^{2}: 0.992\right)$. The pressure in the chamber was determined from the model to avoid introducing a nucleation site via a pressure gauge, and was verified with a firstorder approximation showing good agreement $\left(R^{2}: 0.892\right)$. The $50 \%$ probability of cavitation for distilled water was $-3.32 \mathrm{MPa} \pm 3 \%$, comparable to values in the literature. This novel apparatus, including a closed confinement chamber integrated with a polymeric SHPB apparatus was able to create localized fluid cavitation with loading comparable to blast
\end{abstract}

D. S. Cronin

duane.cronin@uwaterloo.ca

1 Department of Mechanical Engineering, University of Waterloo, 200 University Ave. W, Waterloo, ON N2L3G1, Canada exposure. Future studies will include the measurement of CSF cavitation pressure.

Keywords Cavitation · Polymer split Hopkinson pressure bar $\cdot$ PMMA modelling $\cdot$ Mild traumatic brain injury $\cdot$ Negative pressure

\section{Introduction and Background}

Mild Traumatic Brain Injury (mTBI) is a head injury that results in the alteration or loss of consciousness and is an increasingly important issue identified in military conflicts, with reports suggesting that an estimated 11-23\% of returning US service members screen positive for mTBI. Furthermore, as many as $75 \%$ of all in-theatre blast-related TBI cases are classified as mTBI, suggesting that blast exposure may be a mechanism for mTBI [1, 2]. In contrast to blunt trauma concussions, another form of mTBI, which are generally associated with linear and rotational acceleration of the head, blastrelated mTBI is typically associated with the interaction of a blast overpressure wave and propagation of the wave through the head [3]. The type and symptom severity of mTBI increases with repeated exposure, similar to concussions, but with less understanding of recovery time and symptom frequency $[1,2]$. The causes of mTBI are currently unknown, and there is no consensus in the literature of injury mechanisms resulting in mTBI as a result of blast, which further emphasizes the need for additional research in the topic. Theories of possible injury mechanisms caused by overpressure exposure include soft-tissue damage from shearing [4-7], distortion of cellular structures and cell death in the brain [5, 8-14], and intracranial fluid cavitation [5, 15-19].

With regards to intracranial fluid cavitation, a number of studies have shown that negative pressures can occur in the 
cranium at the opposite side of the initial site of wave transmission during blast exposure [3,16, 19-27], leading investigators to question: (1) does the greater acoustic impedance of the skull compared to its surroundings cause the negative pressures in the cranial cavity, and (2) can the negative pressures generate cavitation of the cerebrospinal fluid (CSF). This paper presents a novel apparatus that can generate localized cavitation in a fluid through high-rate dynamic loading comparable to blast exposure, as a precursor to investigate its effects on the cranial cavity. The goal of the apparatus was to link the reported negative intracranial pressures (ICPs) from the literature with reproducible observable cavitation thresholds.

\section{Background on Cavitation}

The traditional definition of cavitation is the generation of vapour cavities (bubbles) as a result of a drop in pressure in a fluid of constant temperature. Alternatively, generation of bubbles in a fluid of constant pressure as a result of an increase in temperature is described as boiling [28,29]. The occurrence of cavitation can be categorized into homogeneous and heterogeneous nucleation. Homogeneous nucleation occurs when an existing cavity, generally presumed as the result of random molecular motions, exceeds a critical nucleus radius increasing the probability of transforming into a stable vapour phase. The more common type of nucleation seen in application is heterogeneous nucleation, which occurs when bubbles nucleate from existing weaknesses in the fluid such as fluidboundary interfaces, suspended particles, and dissolved gases. Weaknesses occurring at the container boundaries and suspended particles can harbour microscopic bubbles acting as nucleation sites for cavity growth and collapse [28-33]. To observe homogeneous nucleation in a fluid, all weaknesses in the system must be eliminated, resulting in the upper limit cavitation pressure typically reported as the apparent tensile strength of the fluid; however, not all weaknesses in a system can be eliminated, which decreases this upper limit for practical systems. There is a large scatter in reported fluid cavitation pressure thresholds that vary due to differences in experimental methods, rate of loading, temperature, fluid purity, and surface roughness of the container. Furthermore, the probabilistic nature of cavitation requires a large number of tests in order to determine the pressure corresponding to a $50 \%$ probability of generating cavitation $[28,31,32]$.

\section{Dynamic Methods for Generating Cavitation}

There are many methods in the literature that can generate cavitation, but only those applicable to blast exposure such as dynamic methods will be discussed; however, it is worth briefly discussing the acoustic method of generating cavitation because many studies exist and report relatively consistent results in the biological [15, 34-37] and erosion fields [29, 31, 38-41]. The acoustic method for generating cavitation uses periodic high frequency acoustic waves to subject a fluid to cycles of compression and tension as a result of its positive and negative phases, respectively [41]. When the amplitude of the acoustic wave is sufficiently high, cavitation bubbles are generated during the negative portion of the cycle, which partially collapse during the positive portion of the cycle. As a result of the cycles imposed on the bubbles, they undergo asymmetric growth and collapse. That is, the rate of diffusion of dissolved gases into the bubbles is greater than the rate of diffusion of gases out of the bubbles [31, 42-45]. This mechanism of rectified diffusion implies that the periodic wave encourages diffusion of gases into the bubbles and reduces the apparent tensile strength.

A dynamic method developed by Chesterman [46] described as the Tube-Arrest (T-A) method generates direct tensile loading on a fluid column confined in a tube as a result of an arrest in its motion. A tube containing a column of fluid is mounted vertically and attached to springs such that, when extended and suddenly released, the tube and fluid are given an upward velocity. A fixed stop is located in the upward path of the tube and arrests the tube motion as result of impact. After impact, the upward motion of the fluid column generates a tensile wave that is propagated to the bottom of the tube where cavitation is generated. This method is described in greater detail in the works of Hansson et al. [47], Overton et al. [48], and Williams et al. [41, 49-53]. Chesterman performed tests using distilled water in a glass tube with varied impact velocities reporting effects on cavitation cluster dynamics as opposed to its generation. Likewise, Hansson [47] performed tests on water presenting a mathematical model for the formation and collapse of cavity clusters. Overton [48] further developed the method by using a piezoelectric transducer in a cylindrical rubber block forming the base of the tube to measure pressure, and reported the apparent cavitation thresholds of negative $0.178,0.189,0.203 \mathrm{MPa}$ for degassed fresh tap-water, deionized water, and sea-water, respectively. Williams [53] calculated cavitation thresholds as low as negative 56.6-70.2 MPa for 'nuclear-grade' deionized water at $20{ }^{\circ} \mathrm{C}$ using volumetric strains obtained via high-speed imaging.

Another dynamic method described as the Bullet-Piston (B-P) method produces cavitation as a result of a tensile reflection of a generated compressive pulse [41]. A tube containing fluid is mounted vertically with its upper-end exposed to the atmosphere and its bottom-end closed by a sliding-fit piston rod. A compressive pulse is generated by a bullet impact at the open end of the piston rod and propagates into the fluid column. The compressive pulse reflects in tension at the fluid-atmosphere interface as a result of the lower acoustic impedance of the air compared to the fluid. This tensile reflection is limited by the amount of tension the fluid can 
withstand, showing a 'plateauing' of its magnitude with increasing compressive pulse magnitudes, and is reported as the apparent tensile strength of the fluid. This method is described in greater detail in the works of Couzen et al. [54], Sedgewick et al. [55], and Williams et al. [56]. Couzen et al. [57] reported tensile strengths of negative $0.912,0.861$, and $1.52 \mathrm{MPa}$ for boiled water, tap-water, and boiled deionized water, respectively. Similarly, Sedgewick [55] reported tensile strengths of negative $0.912,1.01,1.17$, and $1.47 \mathrm{MPa}$ for tap-water, deionized water, boiled tap-water, and boiled deionized water, respectively. Williams [56] reported tensile strengths of negative $9 \mathrm{MPa}$ along with 4.5 $\mathrm{MPa}$ and $13 \mathrm{MPa}$ as lower and upper bounds, respectively, for 'nuclear-grade' deionized water at $20{ }^{\circ} \mathrm{C}$.

Similar to the B-P method is the fluid-Hopkinson bar method developed by Kenner [58] consisting of a vertically mounted tube with a fluid column, but instead of a short piston rod (110 mm used by Overton et al. [59]), a longer loading rod was used $(610 \mathrm{~mm})$. The longer rod allowed for the generation of a compressive pulse without the need for multiple cycles of reflections described in the B-P method by Overton [59]. The same principle of generating a tensile reflection at the fluidatmosphere interface was used in this method resulting in the 'plateauing' of the reflection magnitude observed in the B-P method. The shape of the compressive pulse was generated by way of a spherical striker propelled by a gas-gun and use of pulse shapers on the loading rod. Using the fluid-Hopkinson bar method, Kenner reported tensile strengths of negative 2.96 MPa [58] and 3.09 MPa [60] for distilled water.

As previously stated, there is a large scatter in reported cavitation pressure thresholds for water that vary due to differences in experimental methods, rate of loading, temperature, purity, and surface roughness of the container [39]. It has been demonstrated in the literature that the T-A method was effective in studying the dynamics of cavitation cluster growth and collapse of fluids, whereas both the B-P and fluidHopkinson bar methods were effective in determining repeatable apparent tensile strengths of fluids for the given system. The main limitations of the methods discussed above with respect to the motivations of studying intracranial cavitation from blast exposure are as follows: (1) A disadvantage arises for the T-A and B-P methods in varying the shape and duration of the incident waves. For the T-A method, input data was typically reported as impact velocity specific to the system, and for the B-P method, varying the input requires different combinations of piston lengths and bullet masses [59]. However, Williams et al. [32] presented an alternate process for varying the input of the B-P method using an increasing static pressure above the fluid column, whereas the fluidHopkinson bar method provides a simpler solution by use of different striker types and pulse shapers. (2) Another notable disadvantage of using the existing methods is the volume of fluid required. The internal diameters of the shortest tubes, used in the T-A method, were $\sim 25 \mathrm{~mm}$, and with a generously low fluid column height of $200 \mathrm{~mm}$ (smallest height reported by Williams [50]), requires $\sim 100 \mathrm{ml}$ of the sample which for some fluids such as CSF would be prohibitive. (3) Lastly, assessing the effect of the higher acoustic impedance of the skull compared to its surroundings requires the option of changing the material at the interface in the cavitation zone. The B-P and fluid-Hopkinson bar method have been designed with a fluid-atmospheric interface, and the additional solid boundary in the vertical orientation of the systems would create challenges with entrapped air between the surfaces during filling. The T-A method allows for changing the boundary by way of replacing the rubber base of the tube, but this option would also create challenges in that seals can harbor nucleation sites or leak in air during severe insults. To overcome these limitations, a novel method of generating localized cavitation was developed. The objective of localized cavitation is to generate repeatable results in a predictable location, avoiding the uncertainty of cavitation occurring as a result of suspended particles or existing microscopic entrapped air bubbles.

\section{Three Apparatus Design Iterations}

The process of designing and validating a method for generating localized cavitation in a fluid through high-rate dynamic loading comparable to blast exposure involved several design iterations. The three main developments are discussed below to provide context for the final design presented in this study, and to highlight important experimental developments in the pursuit of the controlled generation of cavitation. Three iterations of the test apparatus are presented below:

1) T-SHPB-1, a tensile SHPB incorporating a cavitation chamber.

2) T-MCHB-2, a modified tensile Hopkinson bar with a closed-ended cavitation chamber incorporating a pressure transducer.

3) C-MCHB-3, a modified compressive Hopkinson bar with a closed-ended cavitation chamber incorporating a pressure transducer.

In a first iteration (Fig. 15, Appendix A), Singh et al. [61] resolved some of the limitations noted above using a modified SHPB. A traditional SHPB apparatus consists of an incident, transmitter, and striker bar of the same material [62, 63]. Highrate loading is generated by impact of the striker bar on the end of the incident bar, resulting in the propagation of a compressive pulse (incident wave) towards a sample located between the incident and transmitter bars. Once the incident wave reaches the sample, a portion is reflected and propagates back towards the striker-end of the incident bar, and the balance is 
transmitted through the test sample and into the transmitter bar. Singh designed an aluminum tensile SHPB (T-SHPB-1) apparatus and constructed an acrylic confinement chamber that fit over the ends of the incident and transmitter bars, thereby confining the test fluid in the configuration of a traditional test sample. This approach also reduced the volume of fluid required compared to the T-A, B-P, and fluid-Hopkinson bar methods. The fluid sample was sealed between the bars using rubber o-rings around the bar-ends inside the chamber to provide a leak-proof seal without preventing lateral motion. Modifications were made by replacing the striker bar with a concentric aluminum striker tube and affixing an aluminum anvil on striker-end of the incident bar to generate the tensile wave. When the striker tube impacted the anvil, a tensile pulse (incident wave) was generated and propagated into the fluid with cavitation expected at the fluid-transmitter bar interface (back-wall) as a result of the superposition of the incident wave and its reflection occurring at the back-wall. Similar to the fluid-Hopkinson bar method, this method allowed for varying the incident wave by way of combining striker types and pulse shapers, while the use of the transmitter bar provided the higher impedance solid boundary absent from the fluidHopkinson bar method. Singh performed tests on distilled water and reported diffuse cavitation observed in the chamber with a calculated upper bound negative pressure of $1.2 \mathrm{MPa}$ using SHPB theory equations, with the assumption that the water acted as a linear (elastic) fluid. Further development was required as a result of the main limitations of this method: (1) the lack of validation to confirm the negative fluid pressures, and (2) the possibility of air initially trapped in the chamber at the location of the o-ring seals during testing.

In a second iteration (Fig. 16, Appendix A), identified as a Tensile Modified Cavitation Hopkinson Bar (T-MCHB-2), to resolve challenges with the o-ring seals and the presence of air initially trapped in the water, the transmitter bar was removed and the chamber was modified to have only a single opening at the incident bar end. The new chamber provided a continuous solid boundary ensuring no air could leak into the backwall, unlike the o-ring and transmitter bar combination of the T-SHPB-1. This chamber incorporated a side-on pressure transducer (PCB Piezotronics Model 113B21) mounted at the side of the chamber wall to measure water pressure changes. Using this apparatus, Bustamante et al. [64] performed tests on distilled water and reported diffuse cavitation with a measured negative pressure of $0.08 \mathrm{MPa}$. Similarly, a negative pressure of $0.082 \mathrm{MPa}$ was reported by Hong et al. [65]; however, it is worth noting that the transducers used in this iteration and by Hong were designed for compressive (positive) pressures, and did not accurately measure the negative pressures corresponding to cavitation, explaining the relatively low reported cavitation pressures. It was also discovered that tests at higher striker velocities exhibited variability. Therefore, further development was required to address issues with the T-MCHB-2: (1) the challenges in measuring tensile pressure, and (2) the low repeatability of the tensile incident waves generated.

A third iteration (Fig. 17, Appendix A) presented in [64], described as the Compressive Modified Cavitation Hopkinson Bar (C-MCHB-3), was developed with the motivation to resolve the limitations presented for the T-MCHB-2 apparatus. In this case, the apparatus was used in the traditional compressive configuration with the same confinement chamber from the second iteration. A traditional striker bar (711 mm length) was launched by use of a gas-gun, which has been shown to be effective at generating repeatable compressive incident waves $[62,63,66]$. A compressive pulse propagating through the fluid would also be within the measurable range of the pressure transducer mounted in the side of the chamber, and could be used for validating fluid pressure changes. Another reason for using a compressive pulse was to mimic the conditions expected in blast exposure where the initial wave transmitted into the cranial cavity is compressive (primary pressure wave), therefore further replicating the nature of blast exposure conditions [3, 16, 19-27]. The compressive pulse (incident wave) from the incident bar was transmitted into the fluid and through the back-wall of the chamber. Upon reaching the free surface of the acrylic chamber (chamber-end), a reflected tensile pulse (reflected wave) was produced that was transmitted back into the fluid, producing cavitation. In parallel, a numerical model of the apparatus was developed using an explicit multi-physics finite element program (LS-DYNA, Version 971 Revision 6.1.1, LSTC, Livermore CA). The numerical model was in good agreement with the measured incident wave, reflected wave, and positive phase of the water pressure measured (Fig. 18, Appendix A). The water was modelled as a linear fluid and the good agreement of the positive phase of the experimental and numerical pressures gave confidence in the model, and the predicted negative pressure as the upper bound capable for its testing conditions [64]. Tests on distilled water were performed and diffuse cavitation was observed with corresponding predicted negative pressures of 1.32 $\mathrm{MPa}$ and higher from the numerical model [64].

A limitation observed in all three iterations of the test apparatus was the exclusive generation of diffuse cavitation when localized cavitation was desired. Further analysis of high-speed imaging captured using the C-MCHB-3 showed inertial-induced motion of the chamber with respect to the incident bar as a result of the propagating waves. This motion caused an increase in volume of the chamber cavity containing the constant mass of water, resulting in a drop in pressure throughout the fluid, and diffuse cavitation (Fig. 19, Appendix A). Another limitation, regarding the use of a transducer, was observed from high-speed imaging showing trapped air within the transducer port threads being drawn into the water leading to cavitation, and from nuclei occurring at changes in geometry including the port edges and transducer 
diaphragm. Lastly, the loading of the apparatus was limited in that it generated a rectangular incident wave with relatively short duration $(\sim 0.45 \mathrm{~ms})$ as a result of the elastic aluminum striker and incident bars. Whereas the desired loading has a similar shape and duration to the primary pressure wave observed in the frontal region of the cranial cavity as a result of the wave transmission of the primary blast wave into the cranial cavity [3, 16, 19-27].

The important findings from the first three iterations of the apparatus included: the relatively straightforward ability to generate cavitation, albeit diffuse cavitation (estimated cavitation pressures ranged from negative $0.08-1.32 \mathrm{MPa}$ ); the limitations of existing pressure transducers in terms of measuring negative pressures and creating cavitation initiation sites; the importance of achieving consistent fluid conditions; the challenges with o-ring type seals resulting in entrapped air; and the benefit of using a numerical model to predict negative fluid pressures. Due to the limitations noted above for the previous iterations, the cavitation pressure threshold of distilled water was not measured with any of the previous iterations.

\section{Closed-Chamber, Cavitation Hopkinson Bar (C $\left.{ }^{3} \mathrm{HB}-4\right)$ Apparatus}

A fourth iteration apparatus and the subject of the current study, the Closed-Chamber Modified Cavitation Hopkinson Bar ( $\left.\mathrm{C}^{3} \mathrm{HB}-4\right)$, was developed in parallel with a novel numerical model of the apparatus to address the limitations of the previous methods (Fig. 1). A pneumatic system (gasgun) was used to launch strikers towards the acrylic (PMMA) incident bar supported by aluminum and Teflon bearings. The new chamber design, decoupled from the incident bar (described below), was suspended from a fixture (chamber mount) located at the end of the incident bar enabling for lateral motion with minimal constraint after wave transmission.

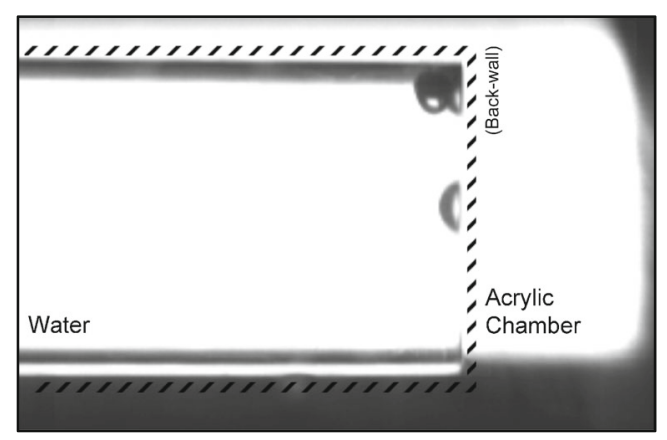

Fig. $1 \mathrm{C}^{3} \mathrm{HB}-4$ apparatus (top) assembly indicating supports, pneumatic system (gas-gun), and chamber mount; and schematic (bottom) indicating steel sphere striker, acrylic incident bar, acrylic confinement chamber, and locations of instrumentation

\section{Geometric Design}

The newly designed apparatus comprises a striker, incident bar, and closed cavitation chamber (Fig. 1). Although a spherical striker is shown, cylindrical bar strikers could also be used with this apparatus. The striker selection is discussed below. A fully enclosed chamber (Fig. 2) was pursued since previous studies demonstrated that open chambers led to the introduction of inertial-induced negative pressure from motion of the chamber with respect to the incident bar (Fig. 19, Appendix A). The chamber was designed with a $25.4 \mathrm{~mm}$ outer diameter to match the diameter of the $2438 \mathrm{~mm}$ long incident bar, ensuring predictable wave transmission between the incident bar and chamber. The dimensions of the chamber were chosen to minimize fluid volume requirements $(1 \mathrm{ml})$ for testing fluids where large quantities may not be available, CSF for example. The side-wall thickness of $9.7 \mathrm{~mm}$ and back-wall thickness of $11.3 \mathrm{~mm}$ were obtained from the varying thickness of the parietal and occipital bone $(\sim 7.4-11.3 \mathrm{~mm})$ of the sagittal head model developed by Singh et al. [19, 67] that used head geometry derived from the Visible Human Project male data set [68]. A transition-fit cap was designed to close the chamber at the leading end. A $0.5 \mathrm{~mm}$ diameter venting channel was cross-drilled through the side-wall of the chamber with its position selected to enable excess fluid to vent from the chamber after filling and installing the cap (Fig. 20, Appendix B). The channel was covered when the cap was fully installed to ensure the chamber was a closed system.

\section{Instrumentation}

High-speed imaging (FASTCAM SA5 Model $1300 \mathrm{~K}-\mathrm{M} 1$, Photron, 50,000 fps with $512 \times 272$ resolution) was used to measure the striker impact velocity. This was not used for all tests, but was used to confirm the repeatability of the pneumatic system to launch the striker at a consistent velocity for model validation, which demonstrated velocities within $1 \%$ or less (§3.4.1). During cavitation tests, high-speed imaging (FASTCAM SA5 Model $1300 \mathrm{~K}-\mathrm{M} 1$, Photron at 100,000 fps with $320 \times 192$ resolution) was framed at the back-wall of the chamber to determine occurrence of cavitation. The high-speed recording was image triggered by the movement of the chamber, and cavitation was identified through frame by frame inspection of the video.

The incident wave was monitored using a strain gauge (CEA-13-250UW-120, Micro-Measurements) mounted at the midpoint of the incident bar and oriented to measure the longitudinal strain in the bar. The strain gauge signal was amplified (2210B Signal Conditioning Amplifier, Vishay) and data was recorded at a frequency of $2 \mathrm{MHz}$ using a high-speed data acquisition system (BNC-2110, National Instruments). This specific instrumentation has been used in several material studies with this apparatus $[69,70]$. A biaxial 


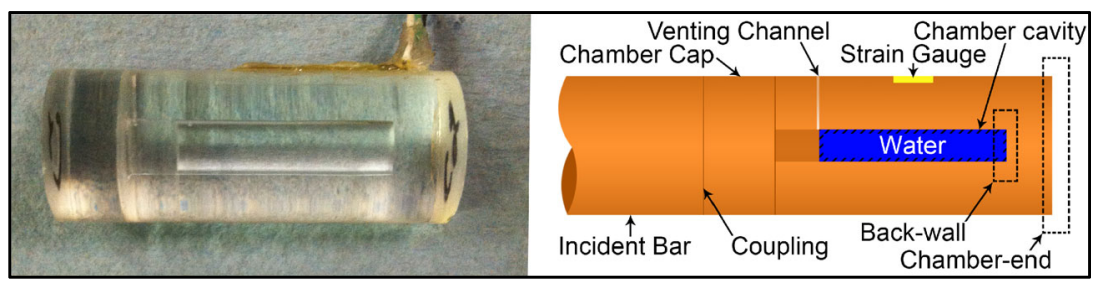

Fig. 2 Acrylic confinement chamber for $\mathrm{C}^{3} \mathrm{HB}-4$ apparatus

strain gauge (WA-09-120WR-120, Micro-Measurements) was mounted on the chamber to measure the longitudinal and circumferential strains in the chamber during the test, using the same amplifier and data acquisition system noted above.

A Photon Doppler Velocimeter (PDV) (1550 nm wavelength, Ohio Manufacturing Institute) was used to measure the velocity of the free surface of the chamber (chamberend) $[71,72]$. Reflective tape was placed on the chamberend to increase its reflectivity ensuring a high signal-to-noise ratio. The pressure transducer used in the previous iterations (e.g. C-MCHB-3) was not included in the chamber design because the small confinement chamber dimensions could not accommodate the pressure transducer, and to prevent the possibility of nucleation sites due to variations in geometry. A numerical model (described below) was used to predict the tensile fluid pressures occurring during the test. A catheter pressure transducer (SPR-524 Mikro-Tip Catheter Transducers, Millar, Inc.) was also investigated; however, three issues were identified: (1) the presence of the transducer introduced nucleation sites and reduced the fluid cavitation pressure; (2) the catheter could not be used over the pressure ranges generated in the tests, with one transducer permanently damaged at negative pressures required to generate cavitation; and lastly, (3) at lower pressures the transducer provided inaccurate measurements due to the impedance difference between the water and the sensing element.

\section{Striker Selection}

Different strikers were considered for this apparatus: a $712 \mathrm{~mm}$ length cylindrical (long) PMMA striker, a $459 \mathrm{~mm}$ length cylindrical (short) PMMA striker, and a $25.4 \mathrm{~mm}$ diameter steel sphere. The traditional cylindrical strikers produced long duration rectangular pulses, but it was found that the pulse intensity was high for typical impact velocities. The spherical striker, accelerated by a preliminary impact with an acrylic striker, was found to produce a pulse shape comparable to the primary pressure waves reported by experimental and numerical blast exposure studies. An example of the incident wave generated by the $\mathrm{C}^{3} \mathrm{HB}-4$ was compared to the primary pressure wave obtained for a $3 \mathrm{~m}$ stand-off distance from $5 \mathrm{~kg}$ of $\mathrm{C} 4$ explosive at a $1.5 \mathrm{~m}$ height burst $[19,67]$ (Fig. 3). It can be seen that the $\mathrm{C}^{3} \mathrm{HB}-4$ incident wave is similar in rate and shape but with a shorter duration, and a steeper decay. The advantage of a short duration incident wave was that the negative pressure, due to the superposition with its tensile reflection, would also have a short duration. Overall, the reproduction of a relatively similar shape of the primary pressure wave was considered appropriate for the goal of the current work.

\section{Numerical Model Development and Validation}

\section{Numerical model of $\mathrm{C}^{3} \mathrm{HB}-4$}

An axisymmetric finite element model of the apparatus was created for the purpose of predicting the fluid pressure changes, since the intrusive nature of a pressure gauge created potential nucleation sites, reducing the fluid cavitation pressure. It should be noted that the numerical model provides the pressure in non-cavitating fluid, since the fluid was treated as a continuum. The apparatus geometry, loading, and boundary conditions were axisymmetric; therefore, axisymmetric elements were used to discretize the geometry. This allowed for a very refined and computationally efficient model. The model was analyzed using an explicit multi-physics finite element solver (LS-DYNA, Version 971 Revision 6.1.1, LSTC, Livermore CA) (Fig. 4). Following a mesh refinement study, a mesh with 203,008 axisymmetric quadrilateral elements ( $\sim 0.40 \mathrm{~mm}$ element size) was used with the acrylic (PMMA) material modelled using an Ogden hyperviscoelastic material model for both the incident bar and

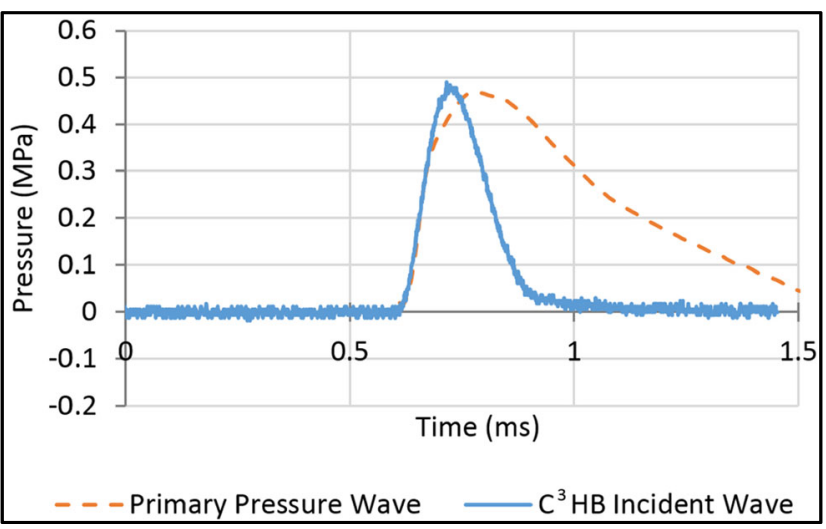

Fig. 3 Primary pressure wave from sagittal head model developed by Singh $[19,67]$ compared to the incident wave pressure trace generated by the $\mathrm{C}^{3} \mathrm{HB}-4$ 
chamber. The water was modelled as a linear fluid, and the spherical steel striker as a linear elastic solid. The water density used was $1.00 \mathrm{~g} / \mathrm{cm}^{3}[52,60]$ with a bulk modulus of $2.19 \mathrm{GPa}[60,73]$. For the steel sphere, a density of $7.840 \mathrm{~g} / \mathrm{cm}^{3}$, a Poisson's ratio of 0.29 , and a Young's modulus of $207 \mathrm{GPa}$ were used $[74,75]$. The interface of the chamber cap and body perpendicular to the propagating pulse was modelled as contacting surfaces while the interfaces between the inner-walls of the chamber and water incorporated shared nodes, since these surfaces were not expected to separate during the simulation time considered.

A single test of the incident bar without the chamber (freeend test) with a spherical striker impact velocity of $9.17 \pm 0.34 \% \mathrm{~mm} / \mathrm{ms}$ (18 psi firing-pressure) was used to determine the Ogden constitutive properties for the acrylic (PMMA) material. The Ogden constitutive model used in the simulations incorporated a multi-term strain energy function [76]:

$W^{*}=\sum_{i=1}^{3} \frac{\mu_{1}}{a_{1}}\left(\lambda_{i}^{* a_{1}}-1\right)+K(J-1-\ln J)$

where $\mu_{1}$ was the shear modulus, $\lambda_{i}^{*}$ was the principal stretch with the volumetric effects removed, $K$ was the bulk modulus, and $J$ was the relative volume. The rate effects were taken into account with a viscoelastic term:

$\sigma_{i j}=\int_{0}^{t} g_{i j k l}(t-\tau) \frac{\partial \sigma_{k l}^{E}}{\partial \tau} d \tau$

where $\sigma_{i j}$ was a linear viscoelastic term, $\sigma_{k l}^{E}$ was the instantaneous stress, and the relaxation function $g(t)$ was the 4 term function:

$g(t)=\sum_{i=1}^{4} G_{i} e^{-\beta_{i} t}$

where $G_{i}$ was the shear relaxation modulus for the $i^{\text {th }}$ term and $\beta_{i}$ was the decay constant of the $i^{\text {th }}$ term. The Ogden hyperelastic constitutive properties were identified through inverse methods using an optimization software (LS-OPT, Version 7.2.1, LSTC, Livermore CA) (Table 1). The resulting model was validated with free-end tests of varying striker types (sphere, cylinder) and velocities. Three repeat tests were performed with firing-pressures of 14,18 , and 22 psi for the short, long, and sphere strikers (Fig. 21, Appendix C). The striker velocities of the 3 repeats were averaged (excluding the sphere striker $18 \mathrm{psi}$ test used to create the model and its 2 repeats), resulting in 24 experimental results and 8 striker conditions simulated (Fig. 22, Appendix C). The 8 conditions were $4.82 \pm 1.4 \%, 6.24 \pm 0.40 \%$, and $7.07 \pm 0.34 \% \mathrm{~mm} / \mathrm{ms}$ striker velocities for the short striker, $4.58 \pm 0.63 \%$, $5.55 \pm 0.25 \%$, and $6.64 \pm 0.66 \% \mathrm{~mm} / \mathrm{ms}$ for the long striker, and $7.57 \pm 0.22 \%$ and $10.36 \pm 0.28 \% \mathrm{~mm} / \mathrm{ms}$ for the sphere striker. Similarly, 27 additional tests with the sphere striker, incident bar, and 3 chambers (chamber tests) filled with distilled water were also performed at varying firing pressures to validate the numerical model incorporating the chamber (3 repeats of 3 firing pressures for 3 chambers).

Cross correlation analysis (CORA software, partnership for Dummy Technology and Biomechanics, Ingolstadt, Germany) was performed to compare the measured and simulated incident bar strain and free-end velocity data for the 8 striker conditions. The measured and simulated strains were compared using three quantifiable characteristics of progression, phase shift, and size, corresponding to their differences in shape, phase, and area, respectively (Table 2). The level of correlation between the signals is known as the rating. The rating ranges between 0 and 1 , with 0 indicating a poor match and 1 indicating a perfect match $[77,78]$. The good agreement between the results indicated that the numerical model could correctly predict the wave propagation in the $\mathrm{C}^{3} \mathrm{HB}-4$ acrylic incident bar at varying striker velocities and for varying striker types. Cross-correlation was also performed on the measured and simulated chamber strain data for the 27 chamber tests, resulting in a good agreement with an average rating of 0.921 , indicating that the model could also predict wave propagation in the acrylic chambers.

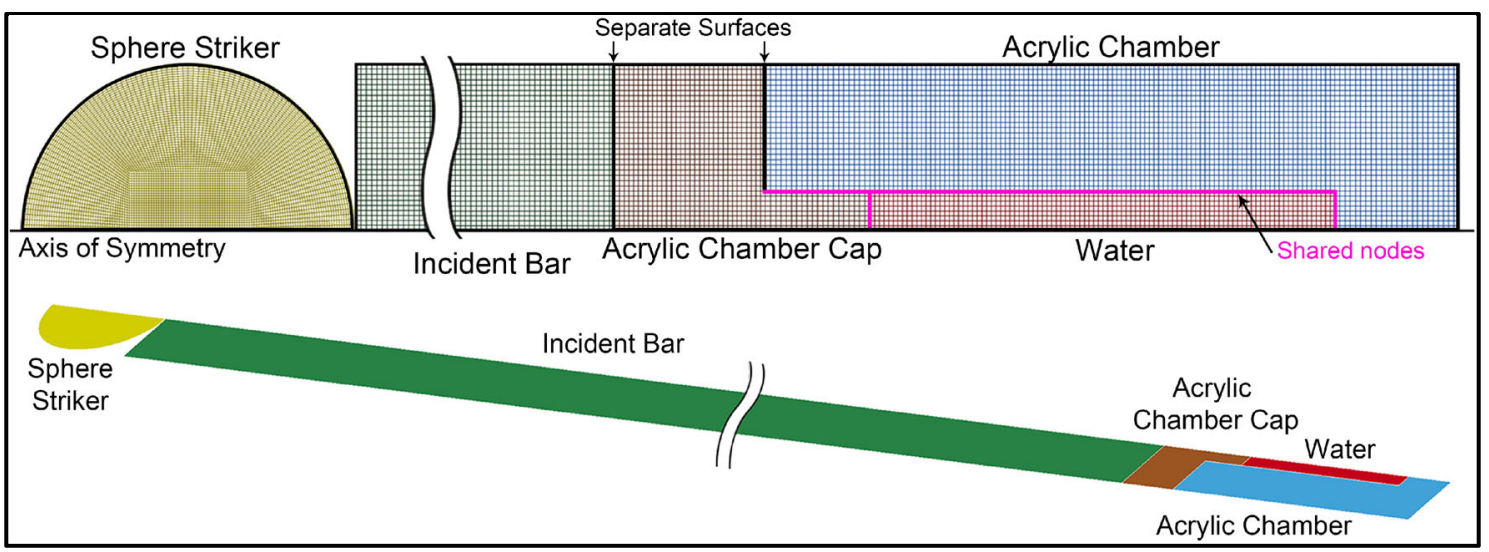

Fig. 4 Axisymmetric finite element model of $\mathrm{C}^{3} \mathrm{HB}-4$ indicating axis of symmetry and discretization of geometry 
Table 1 Acrylic (PMMA) constitutive properties identified through parametric optimization

\begin{tabular}{llll}
\hline $\begin{array}{lll}\text { Density }\left(\mathrm{kg} / \mathrm{mm}^{3}\right) \\
1.183 \mathrm{E}-6\end{array}$ & $\nu$ (Poisson's ratio) & $\mu_{1}(\mathrm{GPa})$ & $\alpha_{1}$ \\
& 0.38 & 3.776 & 1 \\
$\mathrm{G}_{1}(\mathrm{GPa})$ & $\mathrm{G}_{2}(\mathrm{GPa})$ & $\mathrm{G}_{3}(\mathrm{GPa})$ & $\mathrm{G}_{4}(\mathrm{GPa})$ \\
0.00652215 & 0.04924327 & 0.04182822 & 0.13533037 \\
$\beta_{1}$ & $\beta_{2}$ & $\beta_{3}$ & $\beta_{4}$ \\
0.001 & 4.7917 & 28.953 & $12,839.936$ \\
\hline
\end{tabular}

It can be seen that there was good agreement between the arrival times, rise, and peak values for the experiment and simulation, considering both the strain and chamber-end velocity traces recorded (Fig. 5). The differences in the chamber strains observed after the initial compressive (negative strain) phase at $\sim 1.25 \mathrm{~ms}$ were attributed to the complex wave reflections, but occurred after the region of interest. The slightly higher peak value of the measured chamber-end velocity was attributed to the movement of the reflective tape with respect to the chamber, but no explanation for the difference in the settling-velocity after $\sim 1.25 \mathrm{~ms}$ is available at this time. The slight difference in the timing and rise of the reflected wave was attributed to the use of a coupling agent in the experiment that was not implemented in the model, transferring a small amount of tension resulting in a delay of separation between the incident bar and chamber, effectively increasing its magnitude and decreasing its rise-time. Overall, the slight differences between the experiment and simulation occurred after $\sim 1.25 \mathrm{~ms}$, whereas the initiation of cavitation occurred just after $1.1 \mathrm{~ms}$ and collapsed just before $1.25 \mathrm{~ms}$, demonstrating good agreement for the time of initiation and collapse of the first cavitation bubble (discussed in Section 4).

High-speed images of a cavitating test was compared to the water pressure contours predicted in a simulation. It was predicted that the maximum negative pressure occurred uniformly across the diameter in the fluid adjacent to the back-wall surface (within $\sim 2 \mathrm{~mm}$ of the water-acrylic interface) without large variations in the radial direction (Fig. 6). Therefore, cavitation was expected to occur locally within the back-wall region, and bubbles initiating at multiple locations within this region were considered within the criterion of a cavitation event.

Table 2 Cross correlation analysis rating of the acrylic (PMMA) incident bar model validated with measured strain and free-end velocity data from free-end tests for different strikers at varying impact velocities

\begin{tabular}{lll}
\hline Striker & Rating: strain & Rating: free-end velocity \\
\hline Short & 0.988 & 0.984 \\
Long & 0.970 & 0.990 \\
Sphere & 0.997 & 0.993 \\
\hline
\end{tabular}

For verification of the simulated back-wall pressure, a firstorder approximation was calculated following the assumptions that: (1) the wave propagation in the chamber between the water and acrylic was one-dimensional, confirmed by the computational model; (2) the back-wall acrylic surface had the same velocity as the chamber-end; and (3) waves transmitted to the water from the acrylic did not reflect back from the opposite end of the chamber. With these assumptions the pressure at the back-wall was calculated (equation (4)), where $\rho_{\text {water }}$ was the density of the distilled water, $C_{o_{\text {acrylic }}}$ and $C_{o_{\text {water }}}$ were the acoustic wave speeds of acrylic and water, respectively, and $\eta$ was the percentage of energy transmitted from the acrylic to the water (Appendix D). This resulted in a calculated back-wall negative pressure of $2.72 \mathrm{MPa}$, comparable to $2.89 \mathrm{MPa}$ from the numerical simulation with a sphere striker velocity of $9.35 \mathrm{~mm} / \mathrm{ms}$.

$P_{\text {backwall }}(t)=-\rho_{\text {water }}\left[((v(t)-v(t-1)))^{*} C_{\text {oacrylic }}+((v(t-1)-v(t-2)))^{*} C_{o_{\text {water }}}{ }^{*} \eta\right]$

To verify the ability of the apparatus to reproduce negative pressures observed in the head during blast exposure, the back-wall pressure trace simulated from the $\mathrm{C}^{3} \mathrm{HB}-4$ and the occipital region CSF ICP from the sagittal blast head model [19, 67] was compared (Fig. 7). The peak negative value of the CSF ICP from a $3 \mathrm{~m}$ stand-off $5 \mathrm{~kg} \mathrm{C} 4$ explosive charge at a $1.5 \mathrm{~m}$ height burst was matched using the $\mathrm{C}^{3} \mathrm{HB}-4$ numerical model for verification of the pressure traces. The negative pressure phase at the back-wall of the $\mathrm{C}^{3} \mathrm{HB}-4$ model showed good agreement with the negative phase of the CSF ICP from the head model. Similarly, the rate (rise) of the pressure wave in the incident bar showed good agreement with the rate of increase of the primary pressure wave at the frontal region of the head.

The axisymmetric geometry of the chamber resulted in two-dimensional wave propagation when the incident wave entered the chamber from the bar, particularly at the interfaces of different materials. The transition between one-dimensional to two-dimensional wave propagation was observed in the simulation at the interface between the acrylic and water due to its differing acoustic velocity $(1482 \mathrm{~mm} / \mathrm{ms})$ from acrylic $(2198 \mathrm{~mm} / \mathrm{ms})$. Three-dimensional effects could occur locally in the vicinity of the cavitation bubble; however, the goal of the apparatus was to predict the pressure in the fluid up to the point of cavitation, and the model was found to be accurate in that regime.

\section{Test Protocol}

Preparation of the chamber began with a thorough cleaning using regular hand soap to remove any contamination from 
Fig. 5 Experiment (Exp) and numerical (Sim) incident bar strain and chamber-end velocity traces for a single non-cavitating chamber test with a sphere striker impact velocity of $9.35 \mathrm{~mm} / \mathrm{ms}$

Fig. 6 Region of maximum negative fluid pressure identified from the simulation compared to location of cavitation
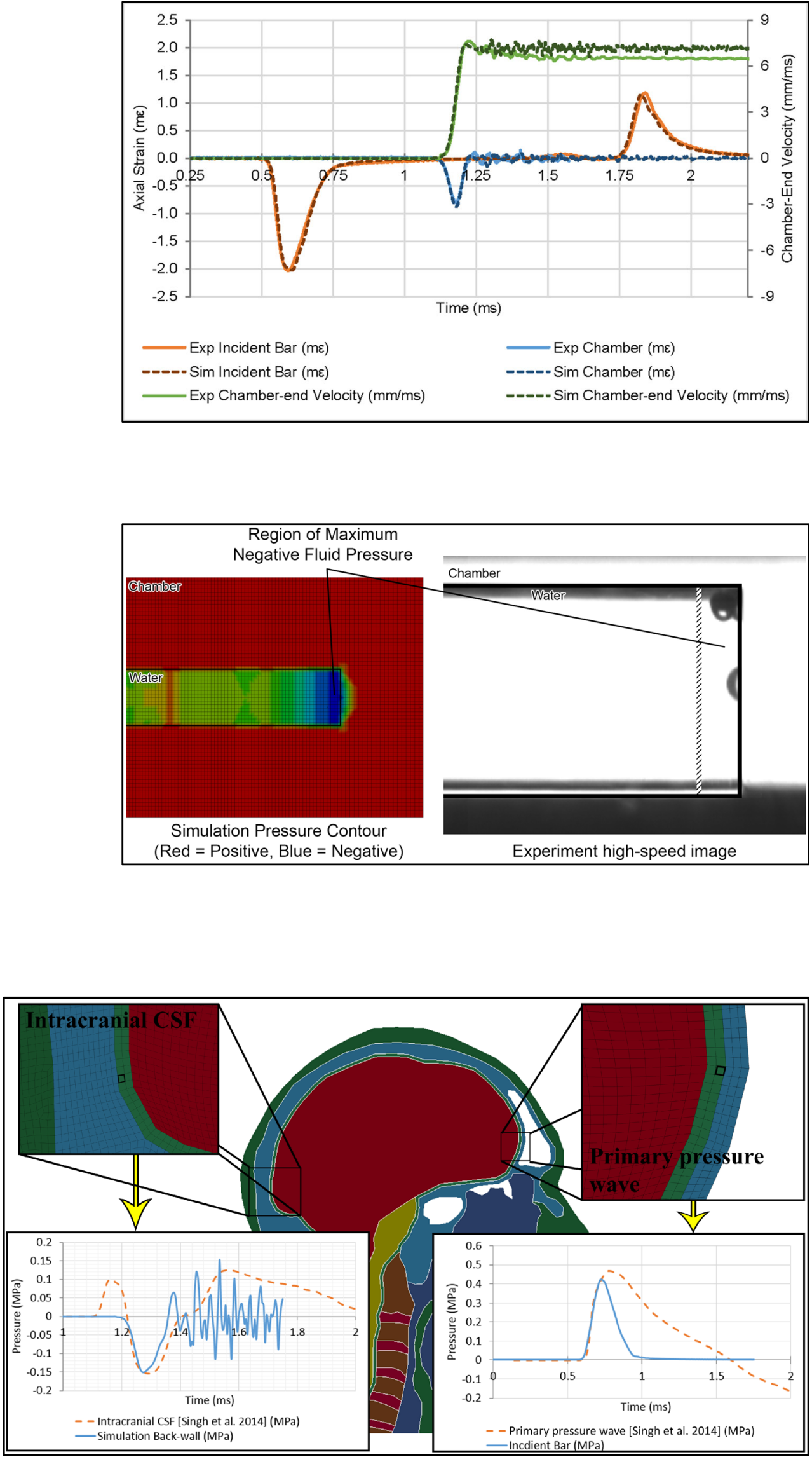

Fig. 7 CSF ICP comparison from $[19,67]$ with predicted pressures from the $\mathrm{C}^{3} \mathrm{HB}-4$ apparatus for $3 \mathrm{~m}$ stand-off blast exposure of $5 \mathrm{~kg} \mathrm{C} 4$ explosive charge at a $1.5 \mathrm{~m}$ height burst 
handling or previous tests. The inside of the chamber was then thoroughly dried and swabbed cleaned with a cotton swab lightly soaked in a dilute isopropyl alcohol and distilled water solution. It was very important that the chamber was completely cleaned of any contamination, such as dust or cotton fibres, ensuring cavitation nuclei were not introduced. The last step required swabbing the inside of the chamber with a lint-free gauze pad carefully removing any visible contamination as a result of the cleaning process. Before filling of the chamber with fluid, a thin film of a low concentration soap solution was applied to the interior of the chamber walls to ensure the distilled water wetted to the walls [79]. The application of the film reduced the surface tension of the water, and therefore discouraged air contamination at the water-acrylic interfaces, which could act as cavitation seeds. Petroleum jelly was used as a coupling agent between the incident bar and chamber to ensure full contact and relieve friction forces [9, 80]. When filling the chamber, care was taken to ensure that the there was no entrapped air in the chamber and the cap covered the venting channel without compressing the fluid inside, thus preserving atmospheric pressure. A strain gauge (WA-09-120WR-120, Micro-Measurements) installed on the chamber confirmed that there was no appreciable pressure induced in the chamber during installation of the cap. Additionally, inspection of the chamber after performing each test indicated no leakage of the fluid from the venting channel occurred during the test.

After impact of the striker sphere with the incident bar, a compressive pulse was generated in the bar and propagated towards the chamber. This compressive pulse was transmitted into the chamber and upon reaching the chamber-end, reflected in tension as a result of the lower impedance of the air compared to the acrylic chamber. When the superposition of the compressive pulse and tensile reflection at the incident bar-chamber interface became negative, it separated the chamber from the incident bar preventing further wave transmission (Fig. 8). The compressive pulse remaining in the incident bar reflected at the now separated interface as a tensile pulse (reflected wave). The tensile reflection pulse in the chamber that caused the separation reflected at the interface in compression and continued to reflect within the chamber.

Considering the wave propagation in the chamber, the compressive pulse $\left(\sigma_{\mathrm{I}(1)}\right)$ from the incident bar was transmitted into the water $\left(\sigma_{I(2)}\right)$ from the cap, and then into the chamber end wall $\left(\sigma_{\mathrm{T}}\right)$. Upon reaching the chamberend, it produced the tensile reflection pulse $\left(\sigma_{R}\right)$, which transmitted back into the water (Fig. 9). Cavitation was expected to occur at the back-wall of the chamber as a result of the tensile reflection pulse $\left(\sigma_{R}\right)$ superimposing with the trailing end of the compressive pulse $\left(\sigma_{I(2)}\right)$; therefore, tests were identified with a positive cavitation result when cavitation bubbles were observed initiating in the back-wall region (Fig. 6).

An initial set of tests was performed with increasing striker impact severity until cavitation was observed. This set of tests provided insight into the lower and upper bound impact severities required for testing. For the following sets of tests, repeats were performed at the lower and upper bounds to verify cavitation and no-cavitation conditions, respectively, and then tests of increasing severity from the lower bound were performed thereafter until the upper bound was reached.

To determine the back-wall pressure in the tests, 10 simulations were performed with increasing severity starting from the lower bound to obtain simulated trends of the incident bar strain, chamber strain, back-wall pressure, and chamber-end velocity. As expected, all the trends obtained were linear and the relationship between the simulated incident bar longitudinal strain and back-wall pressure was obtained. This linear relationship was then used with the measured incident bar longitudinal strain to obtain the back-wall pressure for each test. Using these back-wall pressures with the occurrence of cavitation as data points, a sigmoid probability curve (ISO/TS 18506) was generated to determine the $50 \%$ probability of cavitation [81].

\section{Results and Discussion}

A series of experimental tests (Table 3) were performed with the $\mathrm{C}^{3} \mathrm{HB}-4$ apparatus using three chambers of the same design (identified as $\mathrm{C} 1, \mathrm{C} 2$, and $\mathrm{C} 3$ ), and localized cavitation was successfully generated for distilled water at $21{ }^{\circ} \mathrm{C}$ within the back-wall region of the cavitation chamber where the maximum negative pressure occurred (Fig. 10).

Timing of the occurrence of cavitation was investigated using high-speed imaging coupled with simulated backwall pressure. Analysis of the high-speed imaging demonstrated that the start of the bubble growth occurred at time $\sim \mathrm{t} 1$ (Fig. 11). The bubble continued to grow until $\sim \mathrm{t} 2$ where it reached a maximum volume before recoiling, and then finally collapsing at $\sim t 3$. The initiation corresponded to the onset of the negative pressure. Likewise, maximum volume corresponded to the time of the peak negative pressure and collapse corresponded to the time of the following peak compressive pressure. However, it should be noted that the inertial effects of the bubble growth and collapse may have slight effect on timing. Overall, it has been demonstrated that the timing of the bubble growth and collapse agrees with the pressure traces predicted by the numerical model with cavitation initiating just after $1.1 \mathrm{~ms}$ and collapsing just before $1.25 \mathrm{~ms}$. The differences between experiment and simulation results previously discussed (\$3.4.1) were all observed occurring after $1.25 \mathrm{~ms}$ and therefore are not considered meaningful with respect to the generation of 
Fig. 8 Simplified wave schematic of compressive pulse resulting in the separation of the incident bar and chamber with increasing time (note that complex wave propagation in the chamber is not shown after time t4)
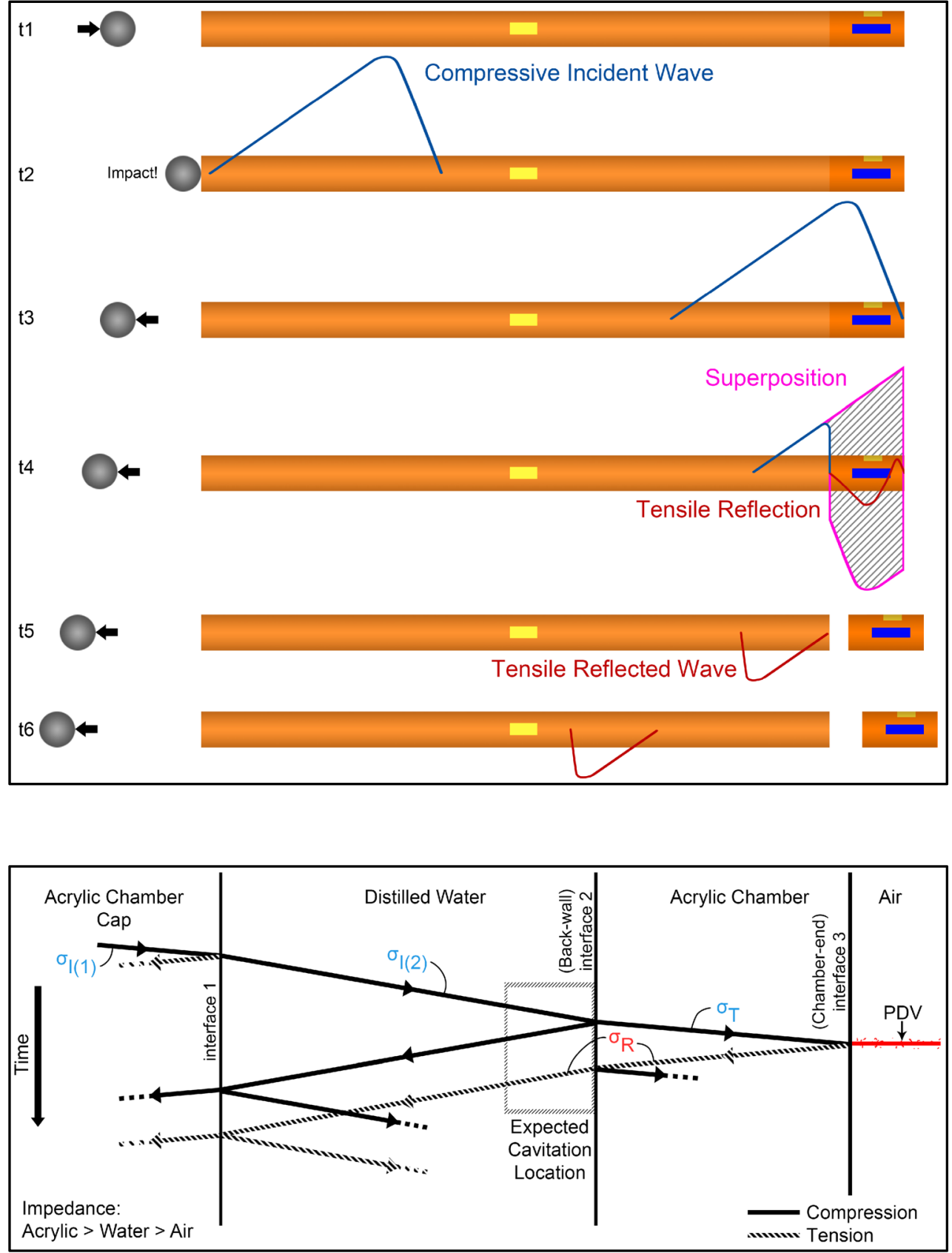

Fig. 9 Wave diagram showing propagation through the chamber to produce negative pressure in the distilled water as a result of the impedance differences between acrylic and air
Table 3 Range of peak compressive longitudinal strains measured in the incident bar and chamber for all tests performed

\begin{tabular}{llll}
\hline $\begin{array}{l}\text { Chamber } \\
\text { performed }\end{array}$ & $\begin{array}{l}\text { Number of tests } \\
(\mathrm{m} \varepsilon)\end{array}$ & $\begin{array}{l}\text { Incident bar strain } \\
(\mathrm{m} \varepsilon)\end{array}$ \\
\hline $\mathrm{C} 1$ & 28 & $1.353-2.796$ & $0.521-1.309$ \\
$\mathrm{C} 2$ & 26 & $1.621-2.577$ & $0.679-1.326$ \\
$\mathrm{C} 3$ & 23 & $1.455-2.781$ & $0.614-1.447$ \\
\hline
\end{tabular}

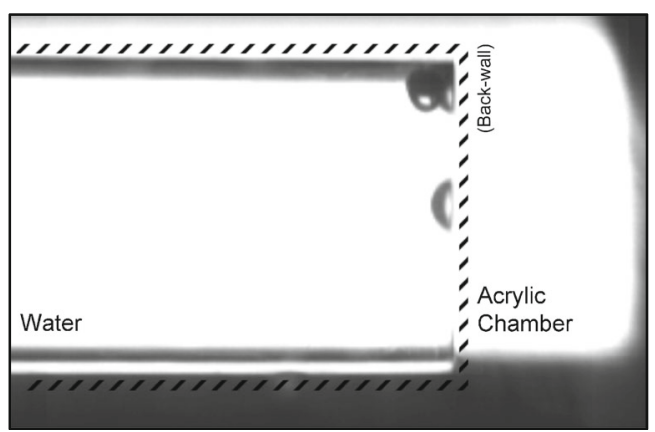

Fig. 10 High-speed image of localized cavitation occurring at the backwall of the cavitation chamber 


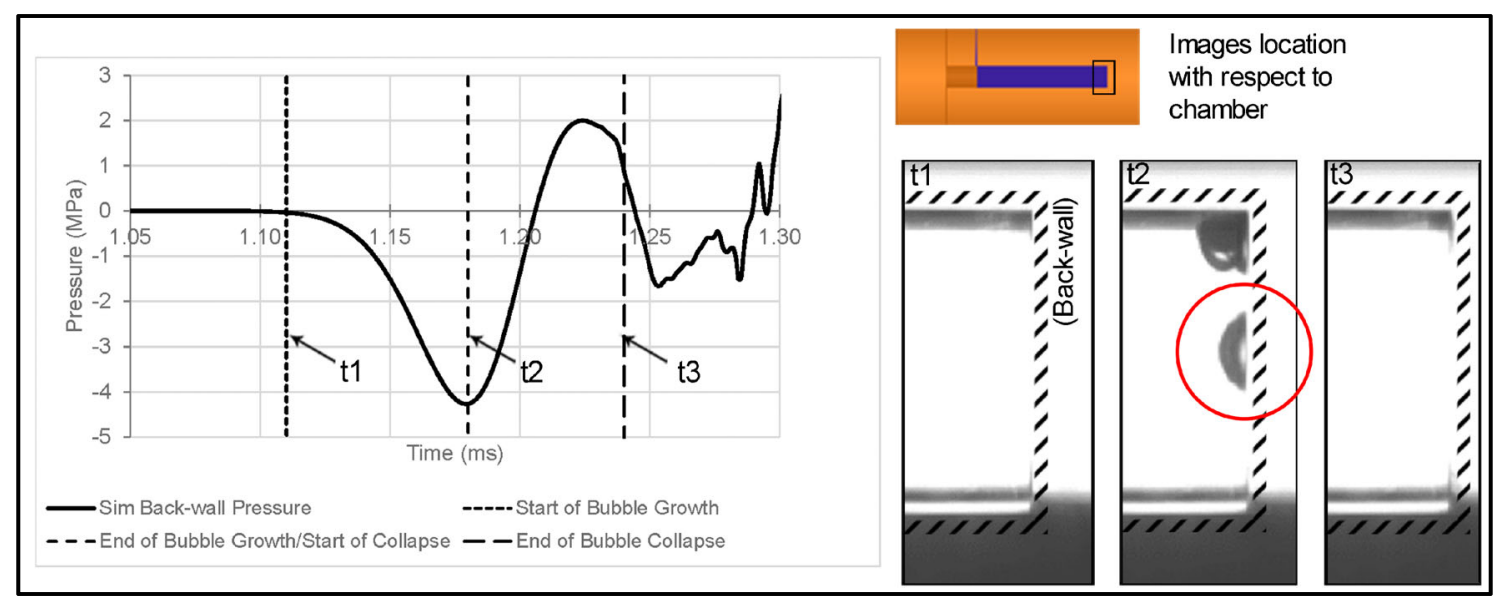

Fig. 11 Timing of bubble (circled) growth and collapse using high-speed imaging coupled simulated back-wall pressure

cavitation initiating at $\sim 1.1 \mathrm{~ms}$. It is worth noting that these differences may have an impact on cavitation bubble dynamics (growth and collapse cycles); however, analysis of bubble dynamics is outside the scope of this study.

Both the experimental and numerical trends of the peak chamber strain and chamber-end velocity with respect to peak incident bar strain for all tests demonstrated good agreement, with $\mathrm{R}^{2}$ values of 0.875 and 0.992 , respectively (Fig. 12). As expected, the trends showed linearity below $50 \%$ probability of cavitation, since without cavitation, the water in the chamber behaves as a continuous fluid.

The calculated (equation (4)) and numerical trends of the peak back-wall negative pressure with respect to peak incident bar strain demonstrated good agreement with an $\mathrm{R}^{2}$ value of 0.892 (Fig. 13). This trend also showed linearity below the $50 \%$ probability of cavitation line, in agreement with the chamber strain and chamber-end velocity trends (Fig. 12).
Sigmoid probability curves were generated for the three sets of separate chamber data, relating the back-wall negative pressure with the occurrence of cavitation observed through high-speed imaging (Fig. 14). For chambers C1, C2, and C3, the negative pressure for $50 \%$ probability of cavitation was $3.36 \mathrm{MPa} \pm 4 \%, 3.52 \mathrm{MPa} \pm 6 \%$, and $3.04 \mathrm{MPa} \pm 4 \%$, respectively.

The probabilistic nature of cavitation near the $50 \%$ mark may explain the differences between the curves; however, it can be seen that the $50 \%$ marks had low variability with a pooled standard deviation of $\pm 5 \%$ and were in good agreement with each other. Combining the data points into one sigmoid probability curve yielded a $50 \%$ probability of cavitation at a negative pressure of $3.32 \mathrm{MPa} \pm 3 \%$, which was comparable with the lower bound reported by Williams (4.5 $\mathrm{MPa}$ ) [56] for 'nuclear-grade' deionized water, which would have a higher pressure because of its greater purity compared with distilled water, and values reported by
Fig. 12 Experimental (Exp) and numerical (Sim) trends of the peak chamber strain and chamber-end velocity with respect to peak incident bar strain Negative incident strains exceeding the $50 \%$ cavitation correspond to a high probability of cavitation

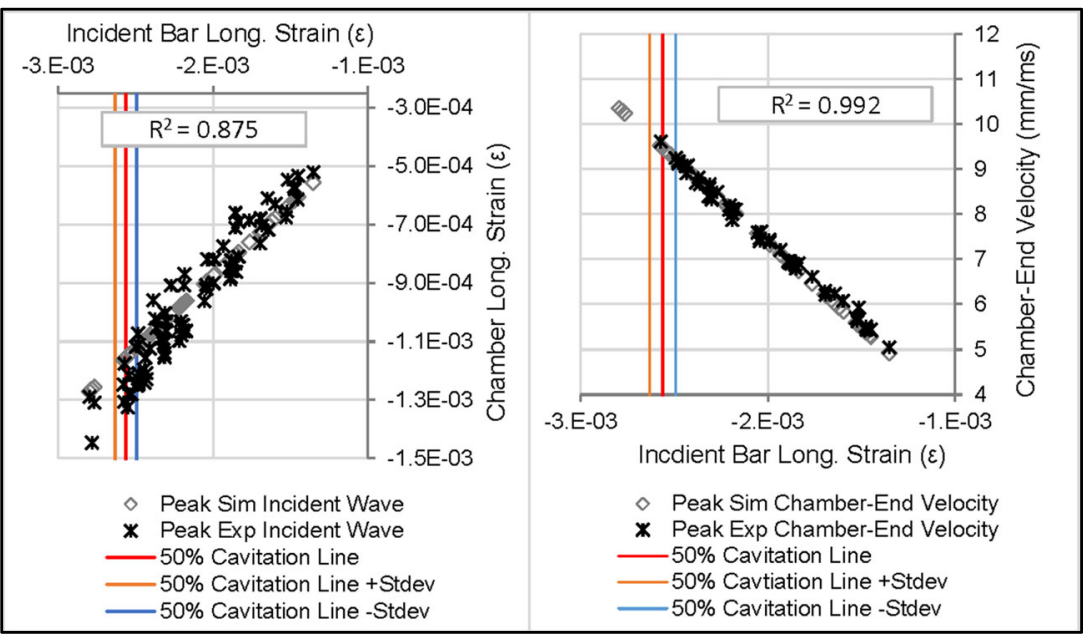


Fig. 13 Calculated and numerical $(\mathrm{Sim})$ trends of the peak back-wall negative pressure with respect to peak incident bar strain

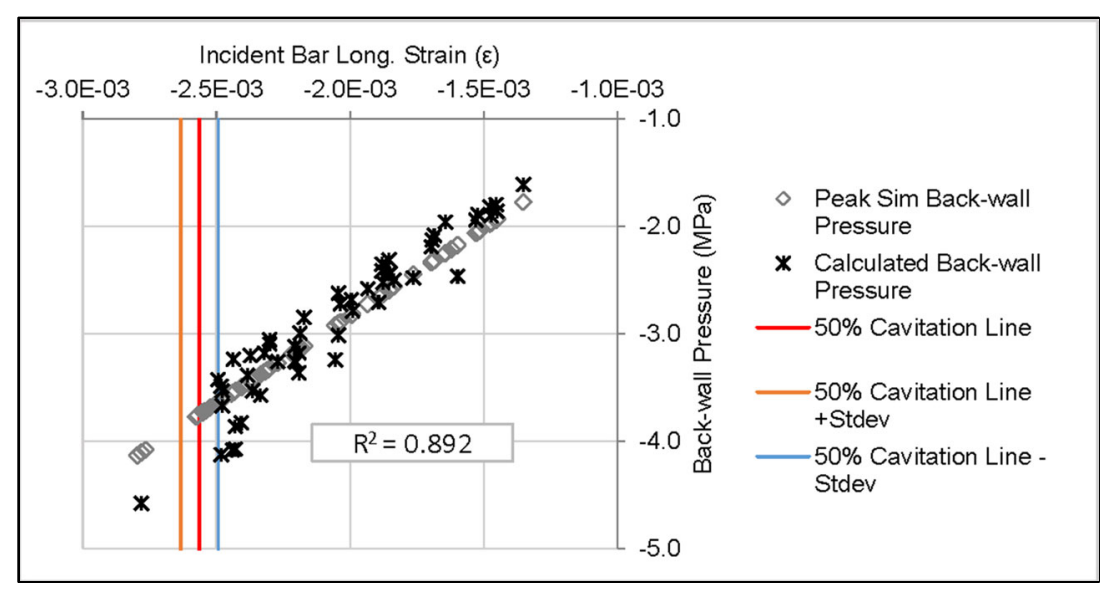

Kenner (2.96, 3.09 MPa) [60] for distilled water. The variability of other reported dynamic techniques ranged between 5 and $10 \%[53,55-57]$. Considering the existing dynamic methods presented in the literature, only the Tube-Arrest method by Williams et al. [53] visually identified cavitating events. The cavitating events reported by Williams also occurred initiating from a solid surface, with one test initiating within the body of the liquid. However, cavitation within the body of the liquid may have been a particular occurrence due to the reported uncertainty of $10 \%$. The proposed $\mathrm{C}^{3} \mathrm{HB}-4$ apparatus provided an important contribution for studying fluid cavitation under controlled and repeatable conditions since this apparatus was able to generate negative fluid pressures similar to that observed in the head during blast exposure, utilize visual identification of cavitation, and measure a cavitation pressure threshold with a standard deviation of $3 \%$.

A methodical approach was followed in the development of the $\mathrm{C}^{3} \mathrm{HB}-4$ apparatus to ensure consistent results with low variability. The sample preparation conditions yielded upper bound cavitation pressure thresholds for distilled water because of the wetting agent used, which discouraged cavitation seeds from occurring at the chamber walls. The negative CSF ICP from a $3 \mathrm{~m}$ stand-off blast exposure of $5 \mathrm{~kg} \mathrm{C} 4$ explosive charge could be recreated with the $\mathrm{C}^{3} \mathrm{HB}$ 4 (Fig. 7); however, when using distilled water with a wetting agent, cavitation was not observed in distilled water.
Fig. 14 Sigmoid probability curves for cavitation at the backwall. Top-left: Chamber 1, Topright: Chamber 2, Bottom-left: Chamber 3, and Bottom-right: Chambers 1-3 plotted together

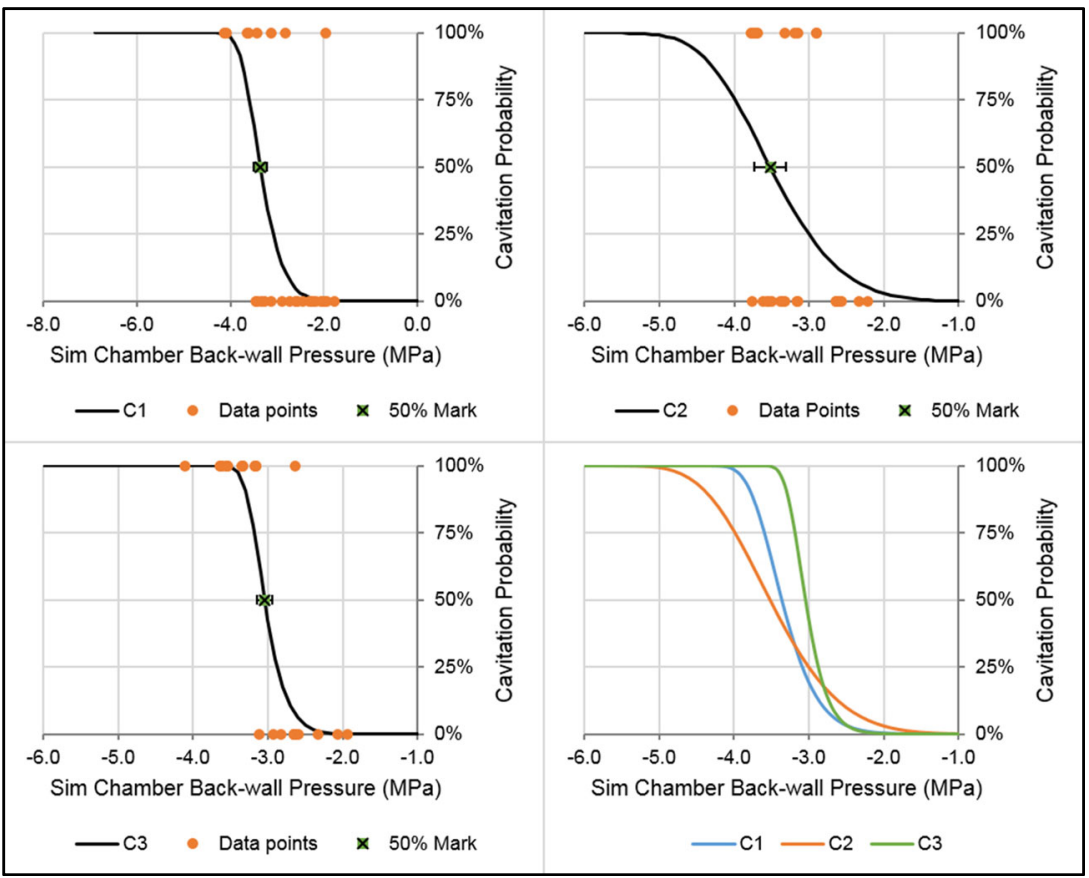


The primary difference between the CSF and distilled water is the higher viscosity of CSF. The bulk modulus is expected to be similar $[25,82,83]$. However, the variation in viscosity is not expected to change the outcome of the simulation since the fluid, and therefore relative motion, is confined. It is expected that, similar to the distilled water testing, the model would be able to predict accurate CSF fluid pressures for non-cavitating conditions. Investigation of the surface properties of the chamber and their relation to in-vivo conditions was outside the scope of the study; however, repeatable surface properties of the chambers was required to have good repeatability of the apparatus, and low variability. Given that the purpose of this study was to develop and demonstrate the apparatus using distilled water, further conclusions regarding blast will be addressed in a future study.

\section{Conclusions}

A series of cavitation apparatus designs incorporating an acrylic (PMMA) fluid chamber and incident bar in a SHPB apparatus were developed to investigate the generation of cavitation in a fluid as a result of dynamic loading. Three iterations of designing and testing resulted in a final design, presented in the current study, which was capable of generating localized cavitation in distilled water using an acrylic (PMMA) incident bar and steel sphere striker coupled with a closed cavitation chamber.

The acrylic chamber was designed to require a low volume of fluid $(1 \mathrm{ml})$ for each test, compared to other dynamic methods for generating cavitation, to perform tests on fluids such as CSF where large quantities may not be available. The chamber wall thickness dimensions were designed to be comparable to those of the skull. The simple geometry for the chamber provided repeatable results that could be interpreted though numerical analysis. The combination of a steel sphere striker and acrylic incident bar generated a compressive pulse comparable to the primary pressure wave observed in blast exposure for both shape and rate, resolving the loading limitations of other dynamic methods. The apparatus also provided the option to vary loading, for example by using different striker geometries.

A finite element model of the apparatus was developed using a single incident bar free-end test with a sphere striker and was validated by predicting the incident bar strains and bar-end velocities for 24 additional experimental free-end tests. For varying striker conditions, the model demonstrated good agreement with the experiments (cross-correlation: 0.970-0.997). Similarly, the numerical model was validated by predicting the chamber strain of 27 additional experimental chamber tests, with the sphere striker at varying impact velocities, resulting in good agreement (average cross-correlation 0.921).

Use of a pressure transducer was rejected after considerations of piezoelectric and catheter-based transducers were found to result in cavitation nucleation sites, and demonstrated inaccurate negative pressure measurements. A strain gauge and a PDV were used as additional instrumentation to link the dynamics of the chamber with the finite element model, resulting in good agreement between the measured chamber longitudinal strain and chamber-end velocity. The agreement of the numerical model in predicting the incident bar and chamber dynamics gives confidence that the fluid pressure changes can be predicted with the model. The peak negative back-wall pressure obtained from the simulations was verified with a first-order approximation based on the PDV results, showing good agreement. Investigation of high-speed imaging coupled with the simulated pressure traces at the back-wall demonstrated cavitation bubble growth and collapse coinciding with the negative and positive pressure phases, respectively. Importantly, the negative phase of the pressure trace at the back-wall predicted by the simulation showed good agreement with the initial negative CSF ICP observed in head blast exposure. Similarly, the pressure wave in the incident bar predicted by the simulation was comparable in magnitude to the pressure wave observed in the head during blast exposure.

Tests were performed on distilled water using 3 different chambers of the similar dimensions and cavitation probability sigmoid curves were generated, resulting in the $50 \%$ probability of cavitation occurring at a negative pressure of $3.32 \mathrm{MPa} \pm 3 \%$, comparable with the lower bound reported by Williams [56] and Kenner [60] using the B-P and fluid-Hopkinson bar method, respectively. Additionally, the apparatus demonstrated lower variability compared to other dynamic techniques used for generating cavitation. The numerical model showed good agreement with predicting the peak incident strains and peak chamber-end velocities of the tests performed having trends with $\mathrm{R}^{2}$ values of 0.875 , and 0.992 , respectively. The numerical and first-order approximation of back-wall negative pressures showed good agreement having trends with $\mathrm{R}^{2}$ value of 0.892 .

In summary, a novel apparatus and method incorporating a closed confinement chamber integrated with a polymer Hopkinson bar apparatus was designed to generate localized cavitation in a fluid through high-rate dynamic loading comparable to blast exposure. A numerical model of the apparatus was developed in parallel that could predict wave propagation and fluid pressures with very good agreement. Tests were performed on distilled water resulting in 3 cavitation probability curves with $50 \%$ probabilities having low variability. The developed method can be applied in the future to provide knowledge of CSF cavitation threshold.

Acknowledgements The authors would like to acknowledge the financial and technical support of Defence Research and Development Canada - Suffield, the Natural Sciences and Engineering Research Council of Canada (NSERC), and the invaluable assistance of Henry Chan in performing experiments. 


\section{Appendix A: First Three Iterations of the Apparatus}

Fig. 15 First iteration tensile TSHPB-1 utilizing an acrylic confinement chamber with tensile split Hopkinson bar apparatus

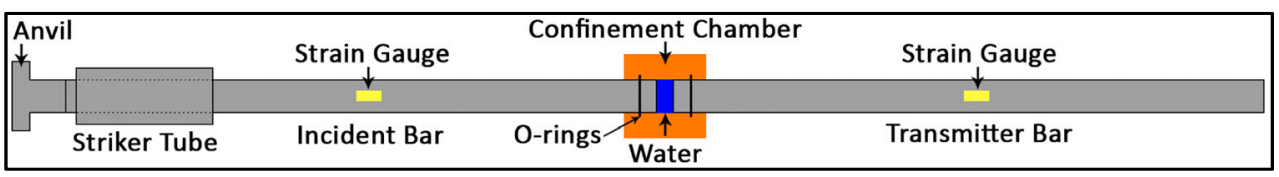

Fig. 16 Second iteration tensile T-MCHB-2 with incident bar and closed-ended confinement chamber including pressure transducer

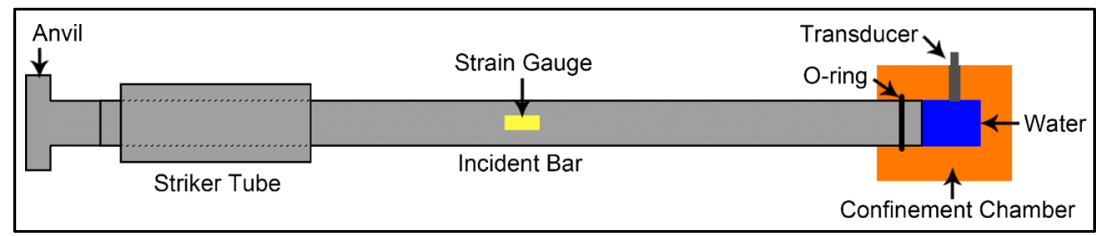

Fig. 17 Third iteration compressive C-MCHB-3, using wave reflection from the chamber back-wall to generate tensile pressures producing diffuse cavitation

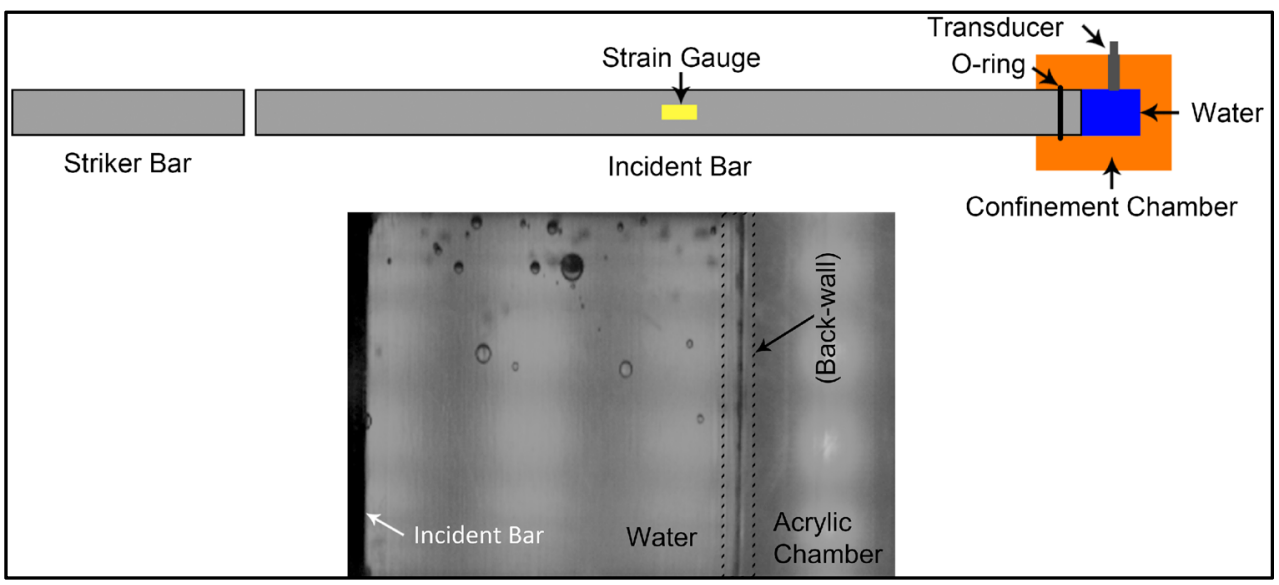

Fig. 18 Comparison of the CMCHB-3 experimental data and numerical model for incident bar pressure and distilled water pressure

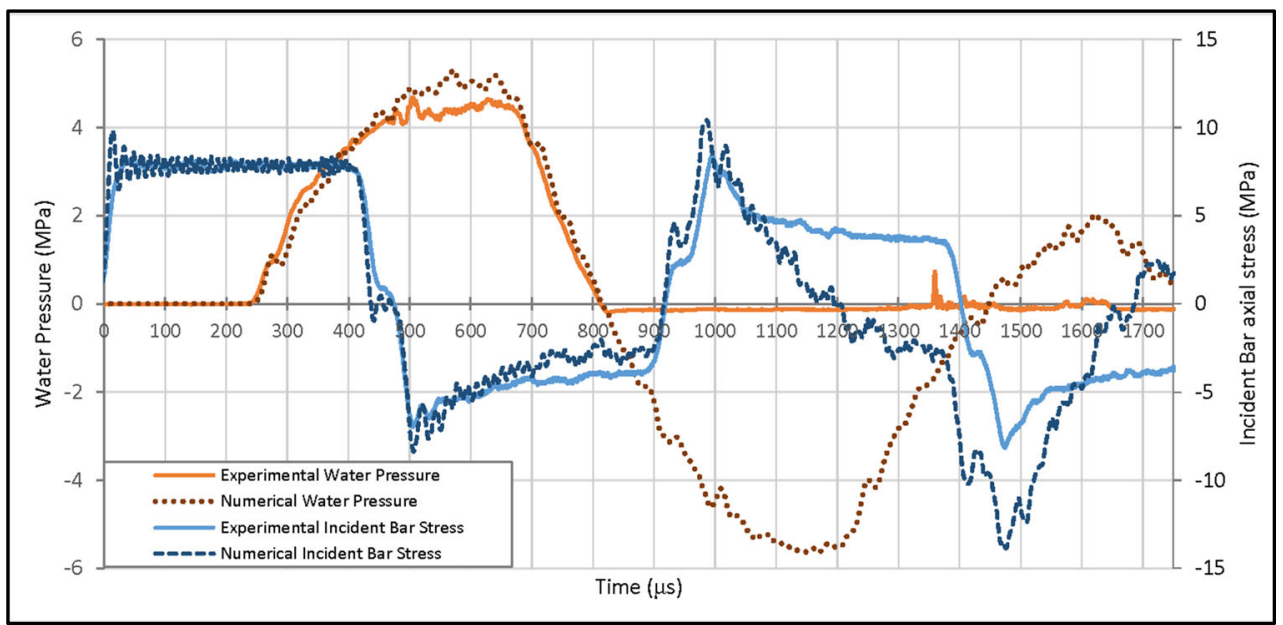

Figure 19 illustrates the increase in chamber cavity volume as a result of chamber motion relative to the incident bar. The compressive incident wave entered the chamber and reflected back-and-forth within the chamber material, which caused relative motion resulting in a drop in water pressure because of the constant mass of water given by: $d P=-K\left(\frac{d V}{V}\right)$

where $K$ was the bulk modulus and $V$ was the volume of water. 
Fig. 19 Relative motion of the chamber in the C-MCHB-3 causing a volume increase in the chamber cavity at time $\mathrm{t} 2>\mathrm{t} 1$

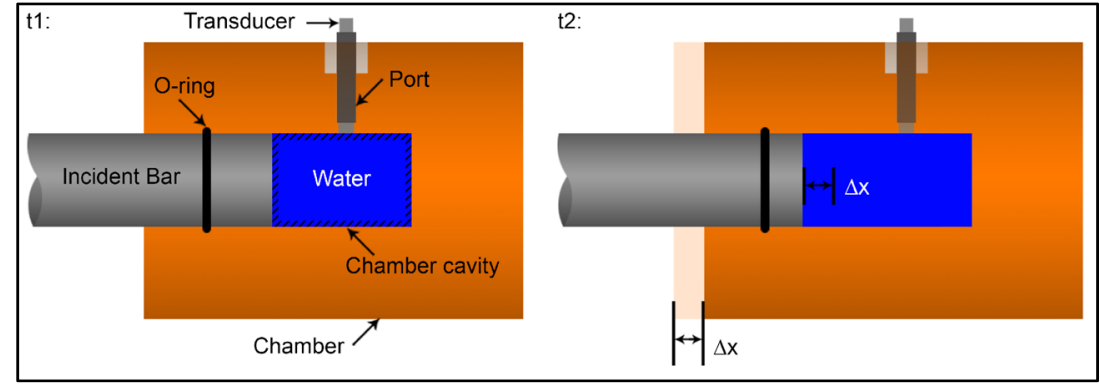

\section{Appendix B: $\mathrm{C}^{3} \mathrm{HB}-4$ Chamber Filling and Venting Channel}

Figure 20 illustrates the process of capping the chamber and the purpose of the venting channel. The channel ensured that the chamber could be closed without the addition of air bubbles and served the purpose of relieving pressure during capping, ensuring fluid pressure remained atmospheric. Care was taken to ensure that the cap would cover the channel without compressing the water retaining atmospheric pressure. This was verified by a strain gauge (WA-09-120WR-120, MicroMeasurements) mounted on the side of the chamber that showed no appreciable pressure was induced in the chamber during installation of the cap.

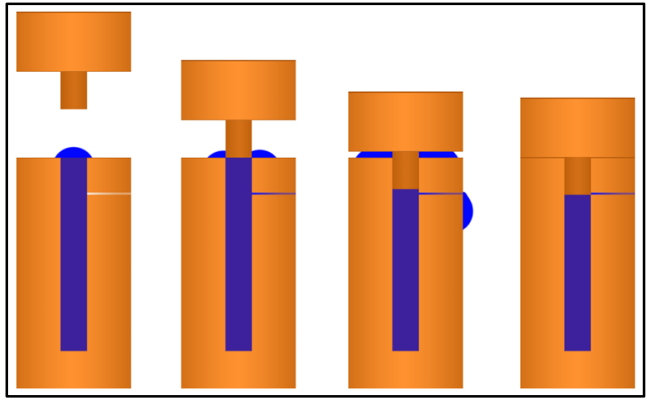

Fig. 20 Process of capping the chamber showing venting of fluid from venting channel

\section{Appendix C: Free-End Test Results}

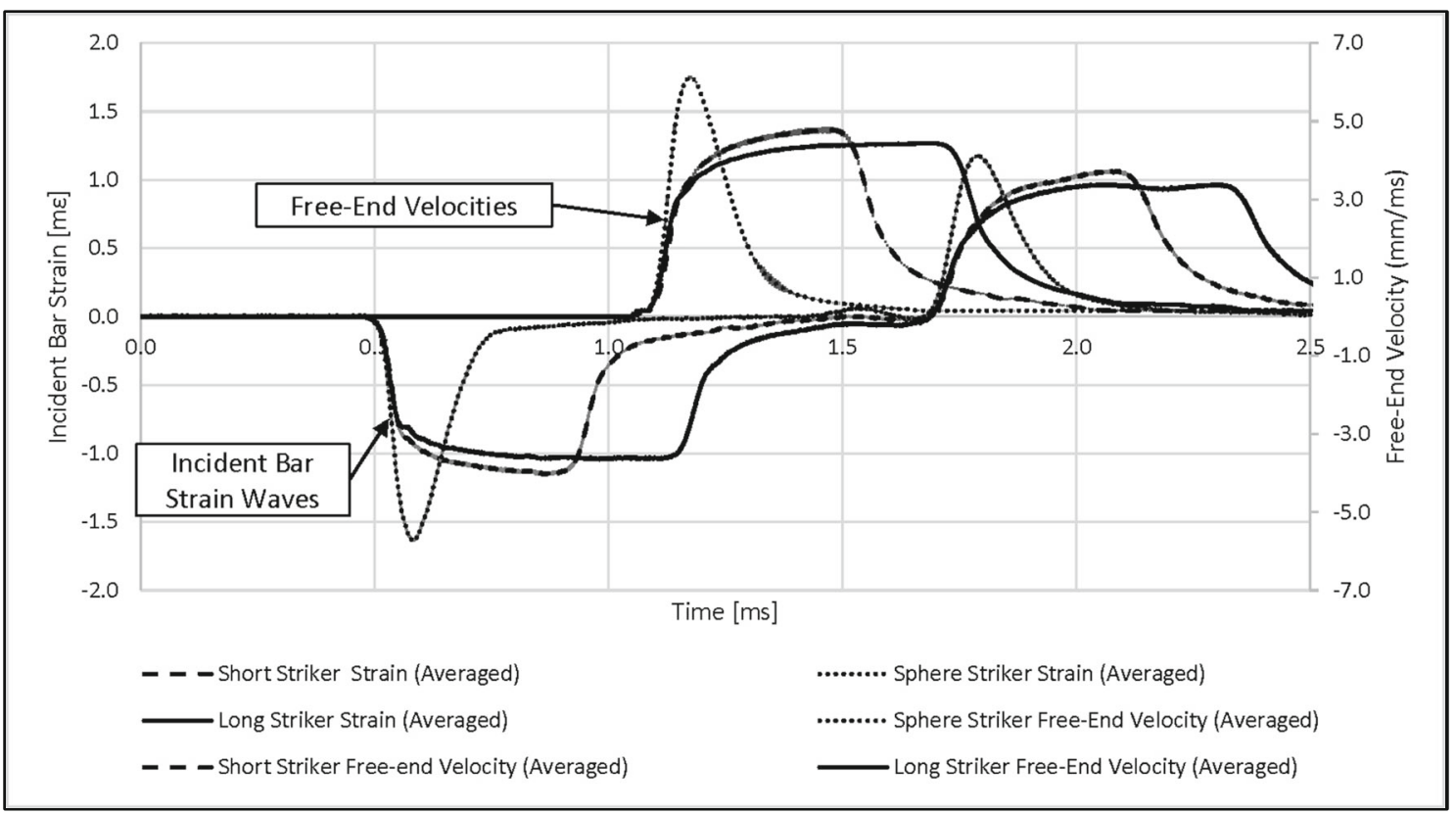

Fig. 21 Example of free-end test (14 psi firing pressure) incident bar strain and free-end velocity results ( 3 repeats averaged) for short, long, and sphere strikers performed for validation. Note that error bars are shown demonstrating repeatability of the apparatus 
Fig. 22 Comparison of incident bar strain and free-end velocity for numerical model (Num) and experimental tests (Exp) with 14 psi firing pressure for sphere, short, and long strikers

\section{Appendix D: First-Order Approximation of Back-Wall Pressure}

The following analytical process used to approximate the pressure at the back-wall of the chamber made the following assumptions: (1) the wave propagation in the chamber between the water and acrylic was onedimensional; (2) the back-wall acrylic surface had the same velocity as the chamber-end; and (3) waves transmitted to the water from the acrylic did not reflect back from the cap of the chamber. A single water element located at the back-wall was created having a water boundary to the left and an acrylic boundary to the right (Fig. 23). Pressure in the element changed as a result of the velocity difference between the water and acrylic boundaries. The change in velocity was the result of the transmission of force to the water from the acrylic. 


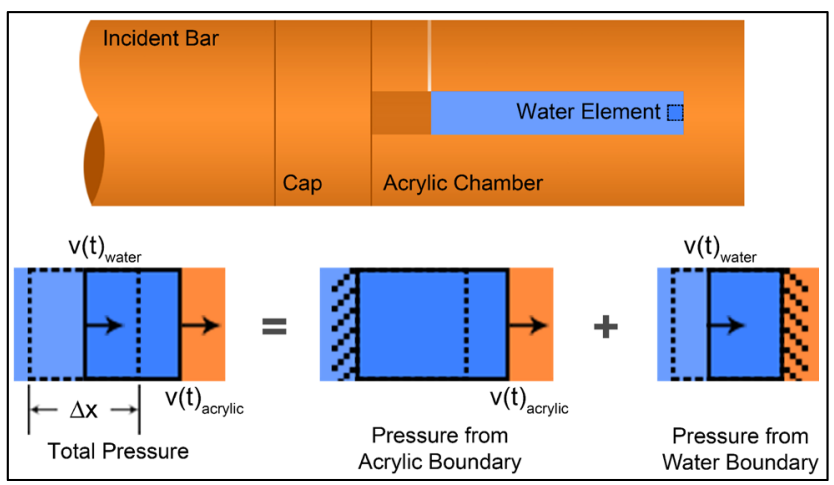

Fig. 23 Location of water element at the back-wall for pressure approximation

The pressure of the element could be approximated by adding the effects of the left water boundary and the right acrylic boundary. The mass of the element was given by:

$\rho=\frac{m}{V}$

where $\rho$ was the density, and $V$ was the volume of the element. Since the chamber cavity was cylindrical and the element was located at its center, the element was given a cylindrical volume with a length of $\Delta x$ :

$m=\rho\left(\pi r^{2} \Delta x\right)$

The pressure force acting on either side of the element can be calculated using:

$P=\frac{F}{A}=\frac{a m}{A}=\frac{\left(\frac{\Delta v}{\Delta t}\right) \rho\left(\pi r^{2} \Delta x\right)}{\pi r^{2}}=\left(\frac{\Delta v}{\Delta t}\right) \rho \Delta x$

where $\Delta v$ was the change in velocity of the side and $\Delta x$ was the element length given by:

$\Delta x=C_{o} \Delta t$

where $C_{o}$ was the acoustic wave speed of element. Since the acrylic boundary was the driver (assumption 2), the velocity history of the water boundary was equal to that of the acrylic boundary but behind a time-step.

The transmitted velocity must be scaled due to the acoustic impedance difference of the water and acrylic. The resistance to acoustic flow of a material is known as its acoustic impedance. The difference between the impedance between two materials affect the magnitude and sense (compressive or tensile) of the transmitted and reflected waves produced during propagation of an incident wave. For an ideal onedimensional wave propagation where the interface between material 1 and material 2 are perpendicular to the incident wave path, an incident wave from material 1 entering material 2 will transmit a portion of its energy as the transmitted wave into material 2 and the remaining energy will be reflected back to material 1 as the reflected wave. The amount of energy disposed to the transmitted and reflected waves are related to the acoustic impedance difference between the two materials. The sense of the reflected wave is also affected such that when the incident wave enters material 2 with greater impedance than material 1 , the reflected wave of the same sense as the incident wave is produced. Whereas if the material 2 has a lower impedance, the reflected wave is of the opposite sense [63]. Therefore, the scale of the velocity transmitted to the water from the acrylic boundary could be calculated by:

$\eta=\frac{\sigma_{\text {transmitted }}}{\sigma_{\text {incident }}}=\frac{2 \rho_{\text {water }} C_{o_{\text {water }}}}{\rho_{\text {water }} C_{o_{\text {water }}}+\rho_{\text {acrylic }} C_{o_{\text {acrylic }}}}$

With the assumption that the water boundary was fixed, the pressure applied by the acrylic boundary could be calculated as:

$$
\begin{aligned}
P_{\text {acrylic }}(t) & =-\left(\frac{\Delta v}{\Delta t}\right) \rho \Delta x=-\rho_{\text {water }} \Delta x\left(\frac{v(t)-v(t-1)}{\Delta t}\right) \\
& =-\rho_{\text {water }} C_{o_{\text {acrylic }}}(v(t)-v(t-1))
\end{aligned}
$$

where the negative indicated a tensile force and $v(t)$ was the velocity measured by the PDV. Likewise, if the acrylic boundary was fixed, the pressure applied by the water boundary was:

$$
\begin{aligned}
P_{\text {acrylic }}(t) & =-\rho_{\text {water }} \Delta x\left(\frac{v(t-1)-v(t-2)}{\Delta t}\right) \\
& =-\rho_{\text {water }} C_{O_{\text {water }}}(v(t-1)-v(t-2))^{*} \eta
\end{aligned}
$$

Therefore the sum of both effects resulted in the pressure of the element given by:

$P_{\text {backwall }}(t)=-\rho_{\text {water }}\left[\begin{array}{lll} & \\ ((v(t)-v(t-1)))^{*} C_{O_{\text {acrylic }}} & \\ +((v(t-1)-v(t-2)))^{*} C_{\text {ouater }^{*}} & *\end{array}\right]$

Open Access This article is distributed under the terms of the Creative Commons Attribution 4.0 International License (http:// creativecommons.org/licenses/by/4.0/), which permits unrestricted use, distribution, and reproduction in any medium, provided you give appropriate credit to the original author(s) and the source, provide a link to the Creative Commons license, and indicate if changes were made.

\section{References}

1. Scherer MR, Weightman MM, Radomski MV et al (2013) Returning service members to duty following mild traumatic brain injury: exploring the use of dual-task and multitask assessment methods. Phys Ther 93:1254-1267. doi:10.2522/ptj.20120143 
2. Dretsch MN, Silverberg ND, Iverson GL (2015) Multiple past concussions are associated with ongoing post-concussive symptoms but not cognitive impairment in active-duty Army soldiers. J Neurotrauma 6:1-6. doi:10.1089/neu.2014.3810

3. Grujicic M, Arakere G, He T (2010) Material-modeling and structural-mechanics aspects of the traumatic brain injury problem. Multidiscip Model Mater Struct 6:335-363. doi:10.1108/ 15736101011080097

4. Alley MD, Schimizze BR, Son SF (2011) Experimental modeling of explosive blast-related traumatic brain injuries. NeuroImage 54: S45-S54. doi:10.1016/j.neuroimage.2010.05.030

5. Sarntinoranont M, Lee SJ, Hong Y et al (2012) High-strain-rate brain injury model using submerged acute rat brain tissue slices. J Neurotrauma 29:418-429. doi:10.1089/neu.2011.1772

6. Nie X, Sanborn B, Weerasooriya T, Chen W (2013) High-rate bulk and shear responses of bovine brain tissue. Int J Impact Eng 53:5661. doi:10.1016/j.ijimpeng.2012.07.012

7. Sosa MAG, De Gasperi R, Paulino AJ et al (2013) Blast overpressure induces shear-related injuries in the brain of rats exposed to a mild traumatic brain injury. Acta Neuropathol Commun 1:51. doi: 10.1186/2051-5960-1-51

8. Ling G, Bandak F, Armonda R et al (2009) Explosive blast neurotrauma. J Neurotrauma 26:815-825. doi:10.1089/neu.2007. 0484

9. Bo C, Balzer J, Brown KA et al (2011) Development of a chamber to investigate high-intensity compression waves upon live cell cultures. Eur Phys J Appl Phys 55:31201. doi:10.1051/epjap/ 2011110052

10. Risling M, Plantman S, Angeria M et al (2011) Mechanisms of blast induced brain injuries, experimental studies in rats. NeuroImage 54: S89-S97. doi:10.1016/j.neuroimage.2010.05.031

11. Bolander R, Mathie B, Bir C et al (2011) Skull flexure as a contributing factor in the mechanism of injury in the rat when exposed to a shock wave. Ann Biomed Eng 39:2550-2559. doi:10.1007/ s10439-011-0343-0

12. Ryu J, Horkayne-Szakaly I, Xu L et al (2014) The problem of axonal injury in the brains of veterans with histories of blast exposure. Acta Neuropathol Commun 2:153. doi:10.1186/s40478-0140153-3

13. Heldt SA, Elberger AJ, Deng Y et al (2014) A novel closed-head model of mild traumatic brain injury caused by primary overpressure blast to the cranium produces sustained emotional deficits in mice. Front Neurol 5:1-14. doi:10.3389/fneur.2014.00002

14. Kamnaksh A, Budde MD, Kovesdi E et al (2014) Diffusion tensor imaging reveals acute subcortical changes after mild blast-induced traumatic brain injury. Sci Rep 4:4809. doi:10.1038/srep04809

15. Lee CS, Frizzell LA (1988) Exposure levels for ultrasonic cavitation in the mouse neonate. Ultrasound Med Biol 14:735-742. doi: 10.1016/0301-5629(88)90029-4

16. Goeller J, Wardlaw A, Treichler D et al (2012) Investigation of cavitation as a possible damage mechanism in blast-induced traumatic brain injury. J Neurotrauma 29:1970-1981. doi:10.1089/neu. 2011.2224

17. Panzer MB, Myers BS, Capehart BP, Bass CR (2012) Development of a finite element model for blast brain injury and the effects of CSF cavitation. Ann Biomed Eng 40:1530-1544. doi:10.1007/ s10439-012-0519-2

18. Hong Y, Sarntinoranont M, Subhash G et al (2015) Localized tissue surrogate deformation due to controlled single bubble cavitation. Exp Mech 97-109. doi:10.1007/s11340-015-0024-2

19. Singh D, Cronin DS, Haladuick TN (2014) Head and brain response to blast using sagittal and transverse finite element models. Int J Numer Methods Biomed Eng 30:470-489. doi:10.1002/cnm. 2612

20. Bir C (2011) Measuring Blast-Related Intracranial Pressure Within the Human Head. Detroit, MI
21. Ganpule S, Alai A, Plougonven E, Chandra N (2013) Mechanics of blast loading on the head models in the study of traumatic brain injury using experimental and computational approaches. Biomech Model Mechanobiol 12:511-531. doi:10.1007/s10237-012-0421-8

22. Hua Y, Kumar Akula P, Gu L et al (2014) Experimental and numerical investigation of the mechanism of blast wave transmission through a surrogate head. J Comput Nonlinear Dyn 9:31010. doi: $10.1115 / 1.4026156$

23. Moss WC, King MJ, Blackman EG (2009) Skull flexure from blast waves: a mechanism for brain injury with implications for helmet design. Phys Rev Lett 103:4-7. doi:10.1103/PhysRevLett.103. 108702

24. Panzer MB, Bass CR, Myers BS (2010) Numerical Study on the Role of Helmet Protection in Blast Brain Injury. In: Pers. Armor Syst. Symp. Quebec City, Canada, p 11

25. El Sayed T, Mota A, Fraternali F, Ortiz M (2008) Biomechanics of traumatic brain injury. Comput Methods Appl Mech Eng 197: 4692-4701. doi:10.1016/j.cma.2008.06.006

26. Zhang L, Makwana R, Sharma S (2013) Brain response to primary blast wave using validated finite element models of human head and advanced combat helmet. Front Neurol 4:88. doi:10.3389/ fneur.2013.00088

27. Zhu F, Mao H, Dal Cengio Leonardi A et al (2010) Development of an FE model of the rat head subjected to air shock loading. Stapp Car Crash J 54:211-225

28. Brennen CE (1995) Cavitation and bubble dynamics. Annu Rev Fluid Mech. doi:10.1017/CBO9781107338760

29. Chahine KKG (2014) Advanced experimental and numerical techniques for cavitation erosion prediction. 106:3-35, 71-95. doi:10. 1007/978-94-017-8539-6

30. Thiruvengadam A (1974) Handbook of cavitation erosion., Rev. ed. Laurel, Md.: Hydronautics. http://oai.dtic.mil/oai/oai?verb= getRecord\&metadataPrefix $=\mathrm{html}$ \&identifier $=$ AD0787073

31. Caupin F, Herbert E (2006) Cavitation in water: a review. C R Phys 7:1000-1017. doi:10.1016/j.crhy.2006.10.015

32. Williams PR, Williams RL (2004) Cavitation and the tensile strength of liquids under dynamic stressing. Mol Phys 102:20912102. doi:10.1080/00268970412331292786

33. Ward JW, Montgomery LH, Clark SL (1948) A mechanism of concussion: a theory. Science (80- ) 107:349-353. doi:10.1126/ science.107.2779.349

34. Fry FJ, Sanghvi NT, Foster RS et al (1995) Ultrasound and microbubbles: their generation, detection and potential utilization in tissue and organ therapy-experimental. Ultrasound Med Biol 21: 1227-1237. doi:10.1016/0301-5629(96)89519-6

35. Ginsberg HJ, Drakeiv JM, Cobbold RSC (2001) Unblocking cerebrospinal fluid shunts using low frequency ultrasonic cavitation. 1381-1384

36. Zhang C, Huang P, Zhang Y et al (2014) Anti-tumor efficacy of ultrasonic cavitation is potentiated by concurrent delivery of antiangiogenic drug in colon cancer. Cancer Lett 347:105-113. doi:10. 1016/j.canlet.2014.01.022

37. Tsaklis P (2010) Presentation of acoustic waves propagation and their effects through human body tissues. Hum Mov 11:91-95. doi: $10.2478 / \mathrm{v} 10038-009-0025-\mathrm{z}$

38. Miller DL (2007) Overview of experimental studies of biological effects of medical ultrasound caused by gas body activation and inertial cavitation. Prog Biophys Mol Biol 93:314-330. doi:10. 1016/j.pbiomolbio.2006.07.027

39. Herbert E, Balibar S, Caupin F (2006) Cavitation pressure in water. Phys Rev E Stat Nonlinear Soft Matter Phys 74:1-22. doi:10.1103/ PhysRevE.74.041603

40. Caupin F, Balibar S, Maris HJ (2003) Limits of metastability of liquid helium. Phys B Condens Matter 329-333:356-359. doi:10. 1016/S0921-4526(02)02103-8 
41. Trevena DH (1984) Cavitation and the generation of tension in liquids. J Phys D Appl Phys 17:2139-2164

42. Temperley HNV, Trevena DH (1977) Metastability of phase transitions and the tensile strength of liquids. Proc R Soc London Ser A Math Phys Eng Sci 357:395-402. doi:10.1098/rspa.1977.0175

43. Temperley HNV, Treverna DH (1987) Why is the tensile strength of water measured dynamically less than that measured statically? J Phys D Appl Phys 20:1080-1081

44. Plesset MS (1970) Effect of dissolved of gases on cavitation in liquids. Pasadena, California

45. Miller DL (1987) A review of the ultrasonic bioeffects of microsonation, gas-body activation, and related cavitation-like phenomena. Ultrasound Med Biol 13:443-470. doi:10.1016/03015629(87)90110-4

46. Chesterman WD (1952) The dynamics of small transient cavities. Proc Phys Soc 65:846-858. doi:10.1088/0370-1301/65/11/302

47. Hansson I, Kedrinskii V, Morch KA (1982) On the dynamics of cavity clusters. J Phys D Appl Phys 15:1725-1734. doi:10.1088/ 0022-3727/15/9/017

48. Overton GDN, Williams PR, Trevena DH (1984) The influence of cavitation history and entrained gas on liquid tensile strength. J Phys D Appl Phys 17:979-987. doi:10.1088/0022-3727/17/5/012

49. Williams PR, Williams PM (1996) Pressure - tension cycles induced by dynamic stressing and cavitation in liquids. J Phys D Appl Phys 29:1904-1909. doi:10.1088/0022-3727/29/7/026

50. Williams PR, Williams PM, Brown SWJ (1997) Pressure waves arising from the oscillation of cavitation bubbles under dynamic stressing. J Phys D Appl Phys 30:1197-1206. doi:10.1088/00223727/30/8/007

51. Williams PR, Williams PM, Brown SWJ (1998) An instrument for studying cavitation phenomena in liquids subjected to tension generated and by free-surface reflection of ab initio compressional waves. Meas Sci Technol 9:976-982. doi:10.1088/0957-0233/9/6/ 015

52. Williams PR, Williams PM, Brown SW (1998) Cavitation phenomena in water involving the reflection of ultrasound pulses from a free surface, or from flexible membranes. Phys Med Biol 43:31013111. doi: $10.1088 / 0031-9155 / 43 / 10 / 028$

53. Williams PR, Williams PM, Brown SWJ, Temperley HNV (1999) On the tensile strength of water under pulsed dynamic stressing. Proc R Soc A Math Phys Eng Sci 455:3311-3323. doi:10.1098/ rspa.1999.0452

54. Couzens DCF, Trevena DH (1974) Tensile failure of liquids under dynamic stressing. J Phys D Appl Phys 7:2277-2287. doi:10.1088/ 0022-3727/7/16/315

55. Sedgewick SA, Trevena DH (1976) Limiting negative pressure of water under dynamic stressing. J Phys D Appl Phys 9:1983-1190. doi:10.1088/0022-3727/9/14/008

56. Williams PR, Williams RL (2000) On anomalously low values of the tensile strength of water. Proc R Soc London A Math Phys Eng Sci 456:1321-1332. doi:10.1098/rspa.2000.0564

57. Couzens DCF, Trevena DH (1969) Critical tension in a liquid under dynamic conditions of stressing. Nature 222:473-474. doi:10.1038/ $222473 \mathrm{a} 0$

58. Kenner VH (1978) The propagation of compressive and tensile waves in a fluid column. Int J Mech Sci 20:373-383

59. Overton GDN, Trevena DH (1981) Cavitation phenomena and the occurrence of pressure- tension cycles under dynamic stressing. J Phys D Appl Phys 14:241-250. doi:10.1088/0022-3727/14/2/016

60. Kenner VH, Wieczorek DC (1980) The response of blood to transient tensile loading. J Biomech Eng 102:151-154

61. Singh D, Cronin DS (2015) Investigation of cavitation using a modified Hopkinson apparatus. Conf Proc Soc Exp Mech Ser 65: 177-183. doi:10.1007/978-3-319-06995-1 27

62. Gray GI, Blumenthal W (2000) Split Hopkinson pressure bar testing of soft materials. ASM Handb Mech Test Eval 8:488-496
63. Kolsky H (1949) An investigation of the mechanical properties of materials at very high rates of loading. Proc Phys Soc B 62:676700

64. Bustamante M, Singh D, Cronin DS (2016) Modified hopkinson apparatus to investigate fluid cavitation as a potential source of injury. Conf Proc Soc Exp Mech Ser 85:43-51. doi:10.1007/9783-319-22452-7 8

65. Hong Y, Canchi S, King M, et al (2012) Development of a test system to study brain tissue damage due to cavitation. In: Am. Soc. Biomech. Gainesville, Florida, p 2

66. Van Sligtenhorst C, Cronin DS, Wayne Brodland G (2006) High strain rate compressive properties of bovine muscle tissue determined using a split Hopkinson bar apparatus. J Biomech 39: 1852-1858. doi:10.1016/j.jbiomech.2005.05.015

67 Singh D (2015) Investigation of primary blast injury and protection using sagittal and transverse finite element head models. University of Waterloo

68 Visible Human Project. U.S. National Library of Medicine, NIH, Bethesda

69 Salisbury C, Cronin D, Lien F-S (2015) Deformation mechanics of a non-linear hyper-viscoelastic porous material, part II: porous material micro-scale model. J Dyn Behav Mater 1:249-258. doi:10.1007/ s40870-015-0027-1

70 Salisbury C, Cronin D, Lien F-S (2015) Deformation mechanics of a non-linear hyper-viscoelastic porous material, part I: testing and constitutive modeling of non-porous Polychloroprene. J Dyn Behav Mater 1:237-248. doi:10.1007/s40870-015-0026-2

71 Strand OT, Berzins LV, Goosman DR et al (2004) Velocitimetry using heterodyne techniques. SPIE Proc 5580:593-599. doi:10. $1117 / 12.567579$

72 Strand OT, Goosman DR, Martinez C, et al (2005) A Novel System for High-Speed Velocimetry Using Heterodyne Techniques. Livermore, California

73 Ganpule S, Cao G, Gu L, Chandra N (2009) The effect of shock wave on a human head. In: ASME 2009 Int. Mech. Eng. Congr. Expo. Florida, p 8

74 AZoM (2012) AISI 1010 Carbon Steel http://www.azom.com/ article.aspx?ArticleID=6539. Accessed 20 Jun 2006

75 Collins JA, Busby HR, Staab GH (2009) Mechanical design of machine elements and machines: a failure prevention perspective, 2nd edn. Wiley, Hoboken

76 LSDYNA (2013) LS-DYNA keyword user's manual volume II: material models

77 Thunert C (2012) CORA Release 3.6 User 's Manual. Ingolstadt, Germany

78 Gehre C, Gades H, Wernicke P (2009) Objective rating of signals using test and simulation responses. Enhanc. Saf. Veh. Stuttgart, Germany

79 Harvey EN, McElroy WD, Whiteley AH (1947) On cavity formation in water. J Appl Phys 18:162-172. doi:10.1063/1.1697598

80 Zhang J, Yoganandan N, Pintar FA et al (2011) Effects of tissue preservation temperature on high strain-rate material properties of brain. J Biomech 44:391-396. doi:10.1016/j.jbiomech.2010.10.024

81 (2014) Procedure to construct injury risk curves for the evaluation of road user protection in crash tests (ISO/TS 18506). International Organization for Standardization (ISO), Geneva, Switzerland

82 Sarvghad-Moghaddam H, Jazi MS, Rezaei A et al (2015) Examination of the protective roles of helmet/faceshield and directionality for human head under blast waves. Comput Methods Biomech Biomed Engin 18:1846-1855. doi:10.1080/10255842. 2014.977878

83 Chafi MS, Karami G, Ziejewski M (2010) Biomechanical assessment of brain dynamic responses due to blast pressure waves. Ann Biomed Eng 38:490-504. doi:10.1007/s10439-009-9813-Z 